\title{
Acute Nontraumatic Muscle Weakness
}

\author{
Kiran Jangra ${ }^{1}$ Hemant Bhagat ${ }^{1}$ Aastha Takkar ${ }^{2}$ \\ ${ }^{1}$ Department of Anaesthesia and Intensive Care, Postgraduate \\ Institute of Medical Education and Research (PGIMER), Chandigarh, \\ India \\ 2Department of Neurology, Postgraduate Institute of Medical \\ Education and Research (PGIMER), Chandigarh, India
}

\begin{abstract}
Address for correspondence Kiran Jangra, DM, Department of Anaesthesia and Intensive Care, Postgraduate Institute of Medical Education and Research (PGIMER), 4th Floor, Nehru Hospital, Chandigarh 160012, India (e-mail: drkiransharma0117@gmail.com).
\end{abstract}

\begin{abstract}
Keywords

- acute weakness

- neuromuscular weakness

- nontraumatic weakness

- respiratory failure

Acute nontraumatic weakness (ANTW) is defined as acute onset of weakness in any part of the body. The weakness occurs due to interruption at any point along the motor pathway. The motor pathway originates from upper motor neuron cells in the cerebral cortex and traverses through the brainstem till lower motor neurons in the spinal cord. The axon of a lower motor neuron is known as the peripheral motor nerve that synapses with muscle. ANTW is of varied etiology and presentation that may be immediately life-threatening if respiratory muscles or autonomic nervous system is involved. Involvement of respiratory muscles may be associated with respiratory failure that may require mechanical ventilation. The weakness may be localized to one limb or generalized involving several muscle groups. When bulbar muscles are involved, weakness leads to problem in swallowing and coughing that endangers the patient's airway. Similarly, the course of the disease also varies, and these patients may worsen rapidly. Hence, a comprehensive history, systematic evaluation, and a detailed neurological examination are performed to localize the disorder. There are specific clinical features peculiar to the particular location of the lesion in the body. Hence, it is possible to anatomically localize these lesions based on the clinical features. Initial laboratory tests and appropriate neuroimaging should be obtained as indicated by history and examination. The time-sensitive emergencies should be addressed immediately, as the delay in management may lead to either permanent neurological damage or may worsen the overall outcome in such conditions. The initial management should always include care of airway, breathing, and circulation (ABC). The imaging should be obtained only after initial stabilization of $A B C$. The definitive treatment should be done as per the etiology.
\end{abstract}

\section{Introduction}

Acute nontraumatic weakness (ANTW) is defined as the sudden onset of paralysis/weakness in any part of the body. The motor functions are controlled by the motor pathway involving upper and lower motor neurons (-Fig. 1). The upper motor neurons (UMNs) arise from the pyramidal cells of the neocortex and pass through the posterior limb of the internal capsule to enter the crus of the midbrain. ${ }^{1}$ The motor tracts then pass through the pons and medulla as the corticospinal tract, which are also known as the pyramidal tracts. ${ }^{1}$ The corticospinal tract divides as the lateral corticospinal tract

received

February 24, 2019 accepted after revision June 19, 2019 published online September 11, 2019 (decussates at pyramids) and the anterior corticospinal tract (crosses at corresponding spinal cord) as these pass down in the spinal cord. ${ }^{1,2}$ Approximately $90 \%$ of motor fibers form the lateral tract, while the rest ( $10 \%)$ form the anterior tract. The lateral corticospinal tracts control the opposite side of the body, while the anterior corticospinal tract neurons control the same side of the body and trunk muscles. ${ }^{1}$ Axons from UMNs synapse with the interneurons in the spinal cord, and occasionally directly with the lower motor neurons. ${ }^{2}$ The lower motor neuron is located in the spinal cord, and its axon projects out of the spinal cord and controls the movement of muscles. ${ }^{1}$ If there is a disease involving any part of the motor
License terms

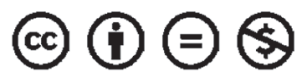

Copyright @2019 Indian Society of Neuroanaesthesiology and Critical Care 


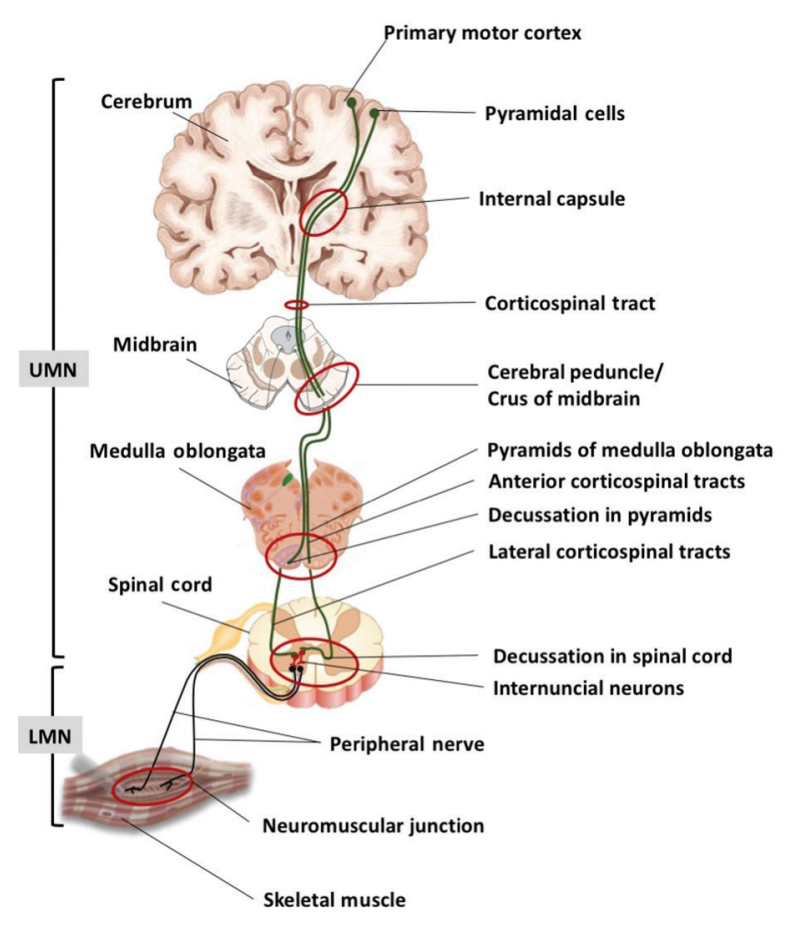

Fig. 1 Diagrammatic representation of the motor tract. It originates from pyramidal cells (motor neuron) of the cerebral cortex as the upper motor neurons (UMNs) and synapse in the spinal cord with lower motor neurons (LMNs). UMN is colored as green, internuncial neuron as red, and LMN as black.

pathway, patients will develop weakness. - Figure 1 depicts the motor pathway.

The etiology of ANTW varies from immediately life-threatening conditions to minor disorders as shown in - Fig. $\mathbf{2 .}^{3}$ The weakness may be localized to one limb or may become generalized involving the respiratory and bulbar muscles. In the latter scenario, protection of airway and care of breathing become the priority. In a few cases, weakness is associated with autonomic disturbances and may lead to hemodynamic instability. Hence, the management of ANTW should include simultaneous resuscitation (care of airway, breathing, and circulation $[A B C]$ ) and evaluation of underlying disease pathology. ANTW is one of the few neurological conditions where delaying the diagnosis and initiation of treatment directly affects the outcome. With a thorough history and clinical examination, we should be able to localize the lesion in many patients or should be able to narrow down the differential diagnosis list.

Here in this review, we discuss the systematic approach to the management of patients with ANTW. Traumatic and chronic weaknesses are beyond the scope of this review.

\section{Initial Evaluation}

The initial evaluation should include the assessment of the patient's ability to protect the $\mathrm{ABC}$ and appropriate measures should be taken to optimize $A B C$ before the neurological examination. ${ }^{4,5}$ Initial neurological examination should be done quickly to rule out time-critical emergencies including

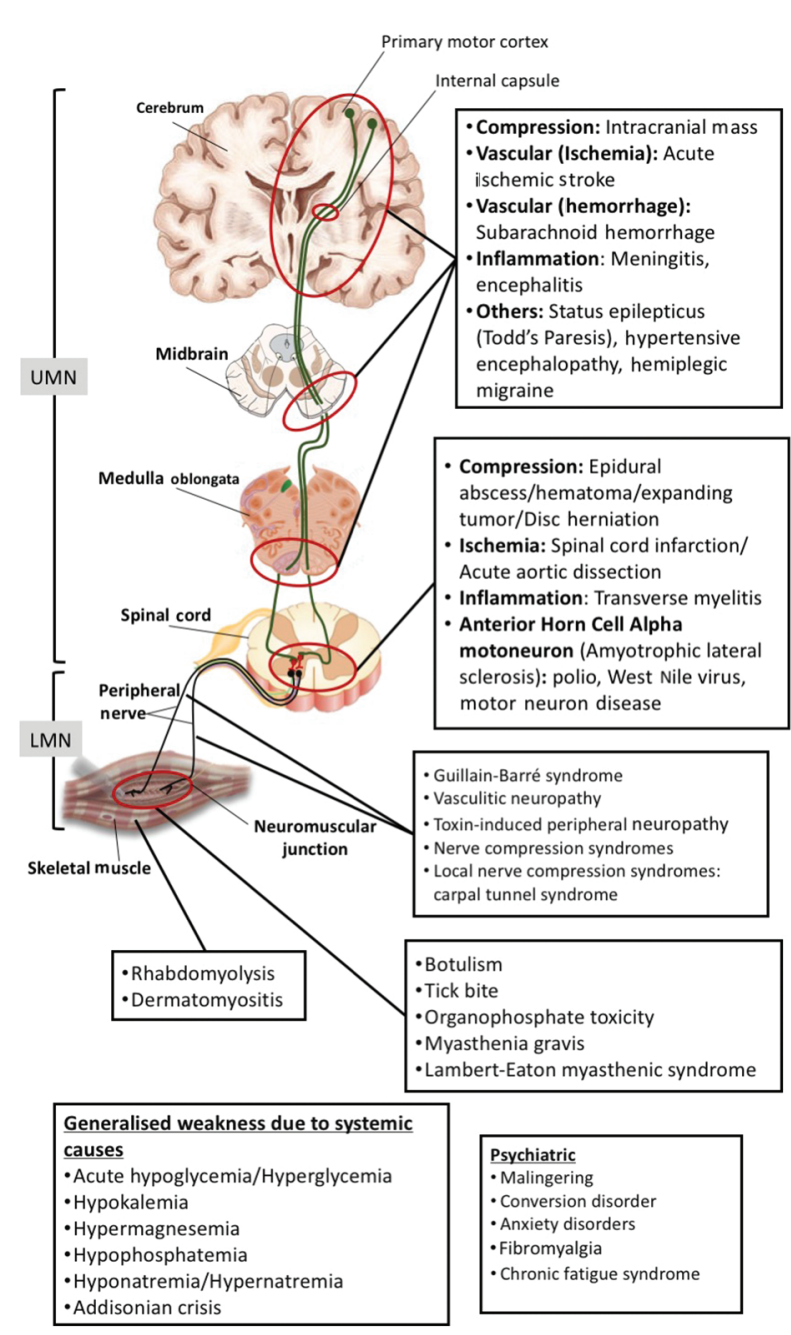

Fig. 2 Diagrammatic representation of various etiologies of acute motor weakness along the motor tract. LMN, lower motor neuron; UMN, upper motor neuron.

acute ischemic stroke, acute spinal cord compression, status epilepticus, dyselectrolytemia, hypoglycemia, and toxin. Various assessment tools are available to assess the neurological status of the patient including the Glasgow Coma Scale, FOUR score (includes eye response, motor response, brainstem response, and respiration), and prehospital stroke scale score. Early recognition and activation of the stroke code system are necessary for optimum outcome in these patients. The acute spinal cord compression may present with flaccid paralysis below the level of insult, and a sensory deficit limited to the involved segment. There may be certain syndromes having their own specific features such as acute cauda equina syndrome that presents with lower severe back pain, sciatica, perineal hypoesthesia, bowel and bladder incontinence, and limb weakness with decreased reflexes. ${ }^{3}$ If toxin exposure is suspected, scene safety should be ensured, and history related to amount and type toxin should be elicited. Initial biochemistry must include blood glucose, electrolytes (sodium, potassium, calcium, magnesium, and phosphorus), kidney and liver function tests, blood coagulation test, and complete blood counts. Relevant imaging should be obtained 
as indicated by history and examination. A detailed motor and sensory examination should be done to locate the lesion anatomically by characteristics of the weakness.

\section{Assessment of Airway and Ventilation}

Neurologically ill patients need airway protection and ventilation if their airway is at risk of aspiration or breathing is inadequate. There are various causes of the airway and respiratory compromise including pharyngeal muscle weakness, leading to the upper airway obstruction and increased risk of aspiration, and respiratory muscle weakness leading to respiratory failure. ${ }^{6}$ Pulmonary gas exchange is usually preserved but may be affected due to atelectasis. Noninvasive ventilation may be tried if the airway reflexes are intact, but respiratory failure occurs due to respiratory muscle weakness. Patients should be monitored regularly as patient's clinical condition may deteriorate rapidly.

Besides the patient's physiology, the plan to intubate is also influenced by the clinical environment and the anticipated course of the disease. If the patient is comatose and needs to be transported to a higher center, for imaging, or other invasive intervention, it would be most appropriate to secure the airway with endotracheal intubation. The patients who are expected to deteriorate in due course of time may need intubation, such as rapidly progressing Guillain-Berré syndrome (GBS). ${ }^{7,8}$ On the other hand, if the patient has a known illness, which is stable and expected to improve, can be managed by noninvasive ventilation.
Various predictors for the need of intubation are enumerated in - Table 1. A combination of clinical signs and objective parameters should be used to predict the need for intubation rather than a single parameter alone. Rapid sequence induction is the preferred modality of emergency intubation in the neurologically ill patients who are at risk of aspiration. ${ }^{9-12}$ Pharmacological agents must be carefully chosen as these patients may be at risk of succinylcholine-induced hyperkalemia (e.g., GBS) or resistant to it (e.g., myasthenia gravis). ${ }^{13,14}$ The patients may be highly sensitive to the sedative-hypnotic agents due to associated autonomic nervous system disturbance.

After intubation, the goals of mechanical ventilation are to normalize oxygenation using the lowest possible inspired oxygen to achieve a hemoglobin saturation $>94 \%$, a systemic $\mathrm{pH}$ of 7.3 to 7.4 , and partial pressure of carbon dioxide or end-tidal carbon dioxide of 30 to $40 \mathrm{~mm} \mathrm{Hg}$, to reduce the work of breathing, and to prevent ventilator-induced lung injury. ${ }^{15}$ Once the patient's ABC are stabilized, a detailed and comprehensive neurological examination is done to localize the lesion.

\section{Clinical and Anatomical Localization}

The cause of weakness can be localized anatomically based on detailed history and examination as the patterns of weakness and associated findings are often specific for each anatomical region. Then we can make a focused differential diagnosis, and specific testing can be done to make an accurate

Table 1 Indications for intubation ${ }^{2,3}$

Clinical symptoms

- Increasing generalized muscle weakness

- Dysphagia

- Dysphonia

- Dyspnea on exertion and at rest

- Unable to remove secretions from the throat

Subjective (clinical signs)

- Tachypnea/hypopnea

- Inadequate chest rise

- Paradoxical respiratory pattern

- Weak coughing ability

- Unable to complete full sentences (gasping for air)

- Inability to perform single-breath count: count from 1 to 20 in single exhalation (FVC $1.0 \mathrm{~L}$ is roughly equal to counting from 1 to 10)

- Use of accessory muscles (cervical/trapezius/nasal flaring)

- Weakness of trapezius and neck muscles: inability to lift head from bed

- Orthopnea

- Tachycardia/hypertension (secondary to sympathetic stimulation due to hypoxia and hypercapnia)

- Sweating

Objective

- Loss of consciousness

- Hypoxemia $(<60 \mathrm{~mm} \mathrm{Hg})$

- PFT findings

-Vital capacity $<1 \mathrm{~L}$ or $20 \mathrm{~mL} / \mathrm{kg}$, or $50 \%$ decrease in VC in a day

-Maximum inspiratory pressure $>-30 \mathrm{~cm} \mathrm{H}_{2} \mathrm{O}$

-Maximum expiratory pressure $<40 \mathrm{~cm} \mathrm{H}_{2} \mathrm{O}$

- Hypercarbia

Abbreviations: FVC, forced vital capacity; PFT, pulmonary function tests; VC, vital capacity. 


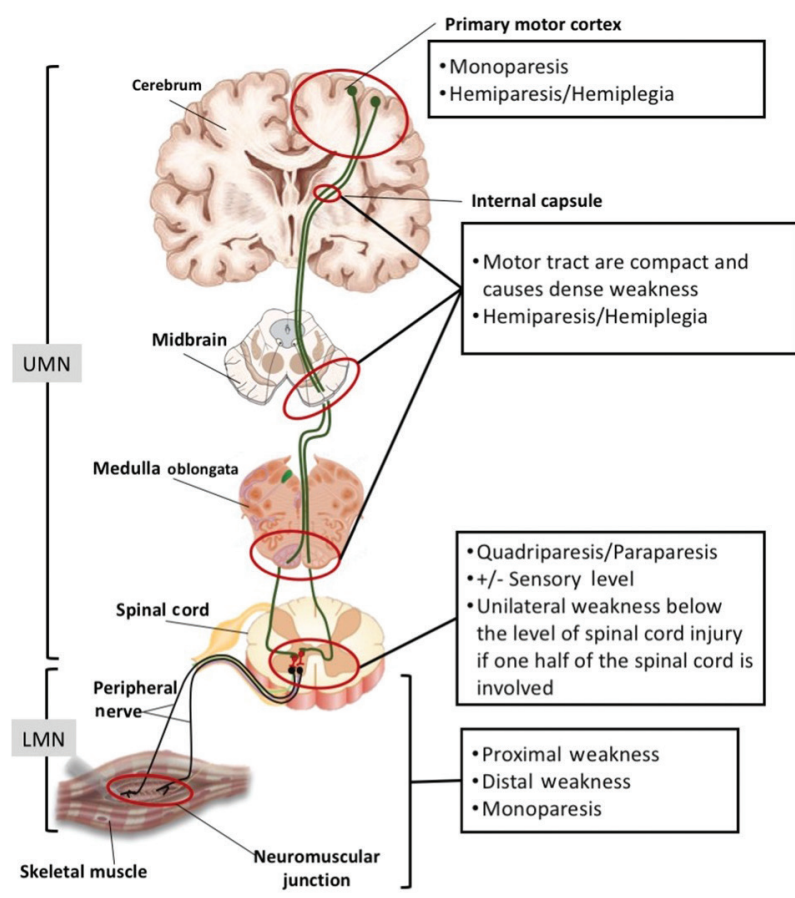

Fig. 3 Diagrammatic representation of clinical localization of the cause of acute nontraumatic muscle weakness based on the pattern of weakness. LMN, lower motor neuron; UMN upper motor neuron. diagnosis. In an obtunded or confused patient, a good clinical history is essential, as such patients may not cooperate for examination. With history and examination, we should be able to elicit whether the weakness is unilateral or bilateral, the pattern of weakness (monoparesis, hemiparesis, paraparesis, quadriparesis or patchy involvement), associated weakness (facial, neck or truncal muscle), the tone of the involved limbs (hypertonia [spasticity or rigidity] or hypotonia), reflexes (normal, diminished or hyperreflexia), and sensory involvement. In a cooperative patient, further evaluation is done to assess the pattern of weakness (symmetrical or asymmetrical, proximal or distal extremities), and sensory modalities affected (pain, fine touch, proprioception, and vibration). The absence of sensory signs (loss of sensations) or symptoms (numbness/tingling) rule out the involvement of peripheral nerves to some extent, and a central nervous system disease should be considered. -Figure 3 and - Table 2 show the localization of various differential diagnosis depending on the clinical features. ${ }^{3}$

With this protocol, we can locate the following anatomical regions: brain, spinal cord, anterior horn cell ( $\alpha$ motoneuron), peripheral nerve, neuromuscular junction (NMJ), and muscle. ${ }^{3}$ The diseases of the brain and spinal cord (central nervous system) lead to "upper motor neuron (UMN) weakness," that is the disruption of descending motor axons or cell

Table 2 Clinical localization of weakness based on pattern of weakness

\begin{tabular}{|c|c|}
\hline Pattern of weakness & Probable differential diagnosis \\
\hline $\begin{array}{l}\text { Hemiparesis/hemiplegia (partial/complete paral- } \\
\text { ysis affecting only one side of the body) }\end{array}$ & $\begin{array}{l}\text { - Acute stroke: ischemic, hemorrhagic, or subarachnoid hemorrhage } \\
\text { - Intracranial mass } \\
\text { - Meningitis/encephalitis } \\
\text { - Hypoglycemia/hyperglycemia } \\
\text { - Postictal Todd's paresis } \\
\text { - Hemiplegic migraine } \\
\text { - Brown-Sequard syndrome }\end{array}$ \\
\hline $\begin{array}{l}\text { Quadriparesis/paraparesis } \pm \text { sensory level (sym- } \\
\text { metrical weakness of either all four limbs or both } \\
\text { lower limbs) }\end{array}$ & $\begin{array}{l}\text { - Spinal cord compression (e.g., epidural abscess, hematoma, expanding } \\
\text { tumor, or prolapsed intervertebral disc) } \\
\text { - Spinal cord infarction: ischemia } \\
\text { - Transverse myelitis } \\
\text { - Generalized weakness: electrolyte and glucose abnormalities }\end{array}$ \\
\hline $\begin{array}{l}\text { Proximal weakness (predominantly affecting the } \\
\text { axial muscles, deltoid, and hip flexors) }\end{array}$ & $\begin{array}{l}\text { - Acute myopathy } \\
\text { - Guillain-Barré syndrome } \\
\text { - Acute diabetic lumbosacral radiculoplexus neuropathy } \\
\text { - Myasthenia gravis } \\
\text { - Acute West Nile virus-associated paralysis } \\
\text { - Lambert-Eaton myasthenic syndrome }\end{array}$ \\
\hline $\begin{array}{l}\text { Distal weakness (weakness mainly affecting the } \\
\text { hands, wrists, and feet) }\end{array}$ & $\begin{array}{l}\text { - Vasculitis neuropathy } \\
\text { - Toxin-induced peripheral neuropathy } \\
\text { - Nerve compression syndromes }\end{array}$ \\
\hline $\begin{array}{l}\text { Monoparesis (paralysis of a single muscle, muscle } \\
\text { group, or limb) }\end{array}$ & $\begin{array}{l}\text { - Acute stroke } \\
\text { - Intracranial mass } \\
\text { - Postictal Todd's paresis } \\
\text { - Nerve compression syndromes } \\
\text { - Diabetic lumbosacral radiculoplexus neuropathy } \\
\text { - Acute poliomyelitis }\end{array}$ \\
\hline
\end{tabular}

Source: Modified from Caulfield et al. ${ }^{3}$ (with permission). 
bodies that innervate the lower motor neurons located in the anterior horn cells of the spinal cord. Lower motor neurons type of weakness is caused by lesions of the anterior horn cells, peripheral nerve, and NMJ. UMN lesions are usually characterized by increased muscle tone, hyperreflexia, and a positive Babinski sign (great toe extension and fanning of fingers). LMN lesions, in contrast, cause flaccidity, areflexic weakness, and fasciculations (involuntary contractions or twitching of muscle fibers). During the acute phase of weakness, the UMN lesions may mimic the LMN lesions and may present with flaccid paralysis, normal or decreased tone, unreliable reflexes, and absent atrophy and fasciculations (occurs after a longer duration of paralysis). ${ }^{16,17}$

The characteristic features, history, clinical examination diagnosis, and treatment of various causes are represented in - Fig. 4.

\section{Approach of a Patient with ANTW}

Irrespective of clinical presentation, the initial management always includes care of $\mathrm{ABC}$. Along with checking the vitals (pulse rate, blood pressure, and temperature), blood sugar should be checked in all patients presenting with weakness. After that, a detailed history and neurological examination are done to make the initial working diagnosis and differential diagnosis. The algorithm suggested by ENLS is shown in - Fig. 5. ${ }^{3}$

The diagnostic tests and definitive management vary greatly from one patient to another and may range from an emergent stroke imaging to elective nerve/muscle biopsy for specific illnesses. Various diagnostic modalities and treatment options for major differential diagnosis are enumerated in - Table 3. After making an initial working diagnosis and differential diagnosis, the patients are further evaluated by various investigations including initial laboratory tests such as glucose, electrolytes (sodium, calcium, magnesium, potassium, and phosphorous), blood urea nitrogen, creatinine, liver function tests, coagulation profile, complete blood counts, and arterial blood gas analysis. If history and examination suggest, certain specific tests may be performed such as thyroid function tests, creatine phosphokinase or CK, erythrocyte sedimentation rate, parathyroid hormone, gamma-glutamyl transferase, serum toxicology, and drug level. Once the patient's $A B C$ are optimized, the relevant imaging is obtained (computed tomography/magnetic resonance imaging [CT/ MRI]). Nerve conduction studies, electromyography, a biopsy of nerve and muscle, and lumbar puncture are to be done if indicated. Patients should be periodically screened for airway and ventilation as these may be involved as the disease progresses. If the examination findings, laboratory tests, and imaging are all within normal limits, then we should consider functional causes such as malingering, conversion disorder, anxiety disorders, fibromyalgia, and chronic fatigue syndrome.

\section{Psychiatric Illnesses}

Conversion disorders are a quite common cause of ANTW and constitute around 5 to $14 \%$ of the cases presenting in

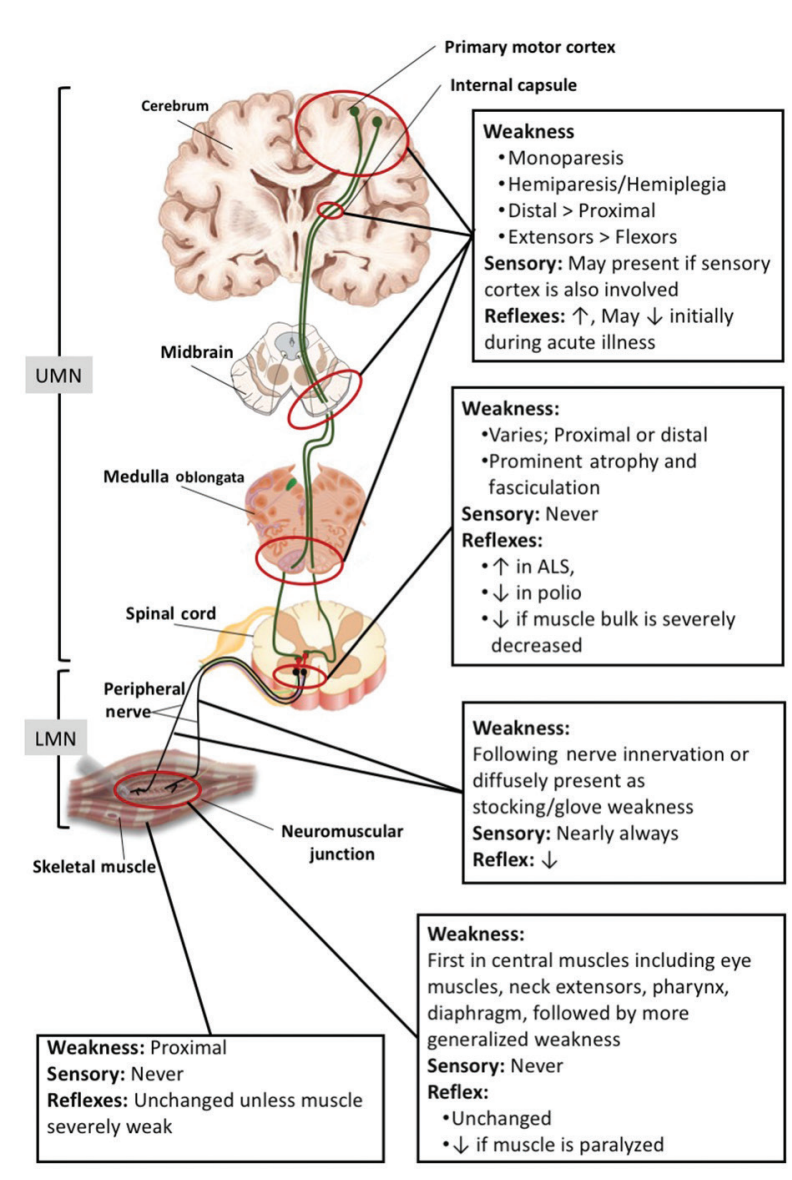

Fig. 4 Diagrammatic representation of anatomical localization of the cause of acute nontraumatic muscle weakness at various levels along the motor tract. LMN, lower motor neuron; UMN upper motor neuron.

the emergency department. ${ }^{18}$ The conversion symptoms may represent a form of communication where patients are not able to express their emotions otherwise, or they may intend to gain attention and rewards from others. The conversion symptoms may originate from a stressful environment where an idea or psychological conflict is converted into somatic symptoms. A detailed psychodynamic assessment helps in making the diagnosis. In psychiatric illnesses presenting as ANTW, the history, clinical examination, initial laboratory tests, and imaging all are inconclusive for any physical illness. Usually, there is a temporal association with psychosocial stressors, and symptom substitution is frequently present. On examination, there is a "La belle indifference" (the person is unconcerned with symptoms) and distribution of weakness does not follow any anatomical pattern. Various investigations, such as MRI/CT and EEG, should be done to rule out organic lesions. Visual-evoked potentials and brainstem auditory-evoked responses should be done to rule out malingering/compensation neurosis if affective or emotional disturbances are found on clinical examination. 


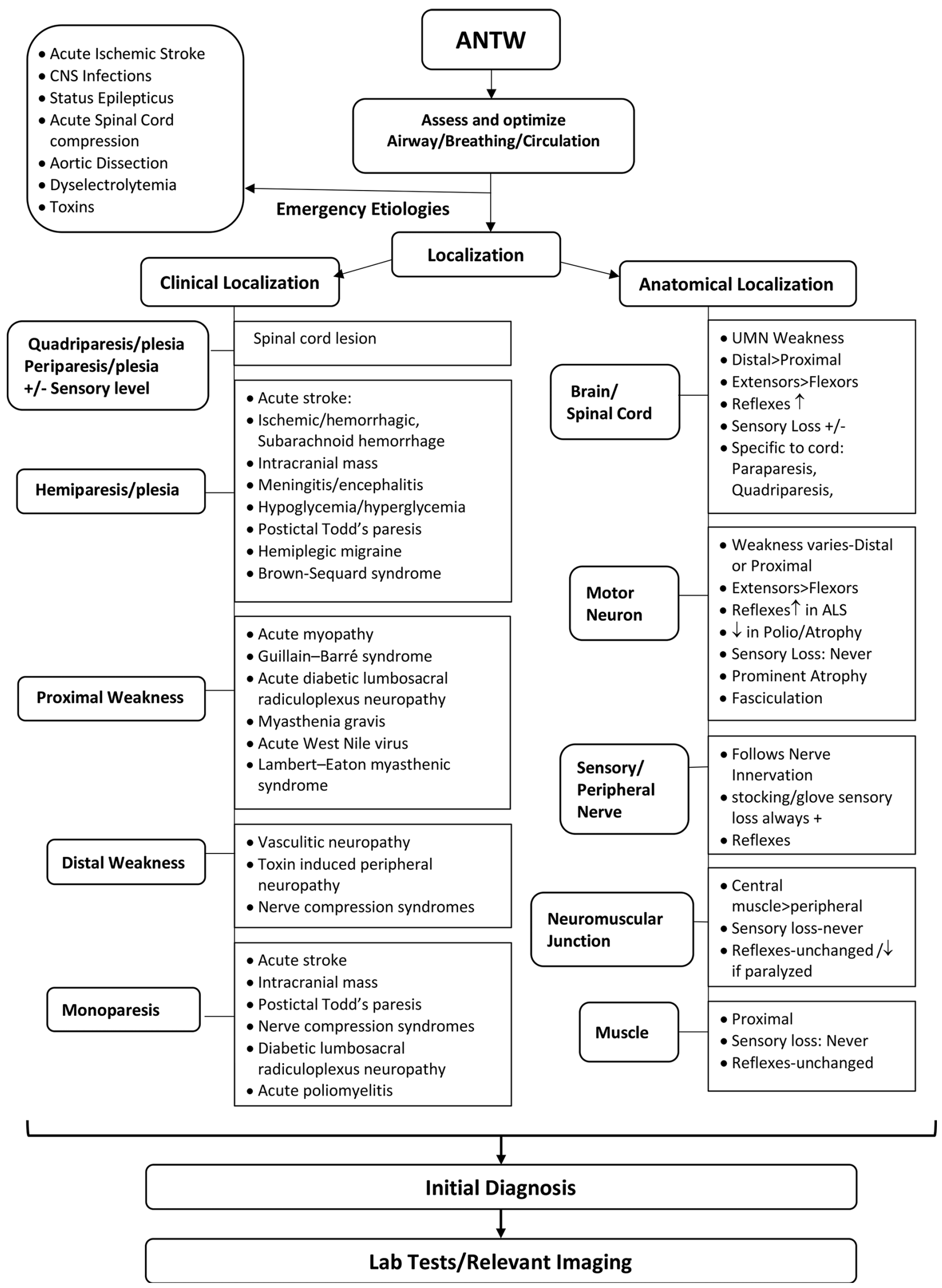

Fig. 5 Algorithm for the management of acute nontraumatic weakness. ANTW, acute nontraumatic weakness; ALS, amyotrophic lateral sclerosis; CNS, central nervous system; UMN, upper motor neuron. Source: Adapted with permission from Caulfield et al. ${ }^{3}$ 
Table 3 Clinical characteristics of various differential diagnosis of acute nontraumatic weakness

\begin{tabular}{|c|c|c|c|c|}
\hline Disease & History & Examination & Investigation & Treatment \\
\hline \multicolumn{5}{|l|}{ Brain lesions } \\
\hline $\begin{array}{l}\text { Intracranial } \\
\text { mass }^{24,25}\end{array}$ & $\begin{array}{l}\text { - Associated symptoms of brain } \\
\text { tumors vary widely depending } \\
\text { up location and size of tumor } \\
\text { - Symptoms and signs of in- } \\
\text { creased ICP } \\
\text { - Local mass effect causes head- } \\
\text { aches, seizures, nausea, ataxia, } \\
\text { and cognitive dysfunction, } \\
\text { focal neurological deficits } \\
\text { - Generalized mass effect pres- } \\
\text { ents as headache, nausea and } \\
\text { vomiting, blurring of vision } \\
\text { - Weakness is UMN/spastic } \\
\text { pattern (upper limb extensors, } \\
\text { lower limb flexors) } \\
\text { - Brain abscess also presents } \\
\text { with similar features along } \\
\text { with fever }\end{array}$ & $\begin{array}{l}\text { - Pupillary asymmetry } \\
\text { - Papilledema on fundus } \\
\text { examination } \\
\text { - UMN type of weakness } \\
\text { - Extensor plantar reflex }\end{array}$ & $\begin{array}{l}\text { - CT head to rule } \\
\text { out other causes } \\
\text { to localize the } \\
\text { lesion } \\
\text { - MRI for detailed } \\
\text { morphology }\end{array}$ & $\begin{array}{l}\text { - Consider steroids } \\
\text { for peritumoral } \\
\text { vasogenic edema } \\
\text { - Manage raised ICP in } \\
\text { the standard step- } \\
\text { wise approach } \\
\text { - Manage blood } \\
\text { pressure and treat } \\
\text { coagulopathy if } \\
\text { there is intracranial } \\
\text { bleed } \\
\text { - Brain abscesses re- } \\
\text { quire targeted anti- } \\
\text { microbial treatment } \\
\text { and sometimes } \\
\text { drainage } \\
\text { Surgical evacuation } \\
\text { and excision of } \\
\text { lesion if indicated }\end{array}$ \\
\hline $\begin{array}{l}\text { Acute ischemic } \\
\text { stroke }\end{array}$ & $\begin{array}{l}\text { - Sudden onset hemiparesis/ } \\
\text { monoparesis } \\
\text { - Faciobrachial syndrome }\end{array}$ & $\begin{array}{l}\text { - UMN type } \\
\text { - On the opposite side of } \\
\text { lesion } \\
\text { - Extensor > flexors in UL } \\
\text { - Flexors > extensors in LL } \\
\text { - Reflexes increased and } \\
\text { plantar extensors on } \\
\text { the side of hemiparesis }\end{array}$ & $\begin{array}{l}\text { - CT head } \\
\text { - MRI brain } \\
\text { (diffusion- } \\
\text { weighted images) } \\
\text { - Angiogram of } \\
\text { neck and intracra- } \\
\text { nial vessels } \\
\text { - ECG/Echocardiog- } \\
\text { raphy to rule out } \\
\text { cardio-embolic } \\
\text { cause }\end{array}$ & $\begin{array}{l}\text { - Stroke protocol } \\
\text { - In acute phase: } \\
\text { thrombolysis/ } \\
\text { thrombectomy } \\
\text { - In later phase: } \\
\text { antiplatelets/statins/ } \\
\text { anticoagulants }\end{array}$ \\
\hline $\begin{array}{l}\text { Postictal Todd's } \\
\text { paresis }^{26,27}\end{array}$ & $\begin{array}{l}\text { - } \text { More common after prolonged } \\
\text { seizures (status epilepticus) } \\
\text { - Self-limiting and lasts for sec- } \\
\text { onds or up to hours }\end{array}$ & $\begin{array}{l}\text { - Transient weakness } \\
\text { - Weakness varies } \\
\text { widely in location, } \\
\text { severity, duration, tone } \\
\text { reflexes, and sensory } \\
\text { involvement }\end{array}$ & $\begin{array}{l}\text { CT head to exclude } \\
\text { other causes of } \\
\text { weakness }\end{array}$ & - Supportive \\
\hline
\end{tabular}


Table 3 (Continued)

\begin{tabular}{|c|c|c|c|c|}
\hline Disease & History & Examination & Investigation & Treatment \\
\hline $\begin{array}{l}\text { Hypertensive } \\
\text { encephalopa- } \\
\text { thy } 28,29\end{array}$ & $\begin{array}{l}\text { - Long standing, poorly con- } \\
\text { trolled hypertension } \\
\text { - Poor compliance with antihy- } \\
\text { pertensive agents, } \\
\text { - Headaches, confusion, visual } \\
\text { disturbances, nausea, and } \\
\text { vomiting }\end{array}$ & $\begin{array}{l}\text { - Severe, sustained } \\
\text { hypertension } \\
\text { - Transient, migratory } \\
\text { neurological non-focal } \\
\text { deficits, ranging from } \\
\text { nystagmus to weak- } \\
\text { ness, and an altered } \\
\text { mental status, ranging } \\
\text { from confusion to coma } \\
\text { - Funduscopic may reveal } \\
\text { f/s/o HTN retinopathy- } \\
\text { papilledema, hemor- } \\
\text { rhage, exudates, and } \\
\text { cotton wool spots }\end{array}$ & $\begin{array}{l}\text { - CT head } \\
\text { - Urine toxicology } \\
\text { screen } \\
\text { - Coagulation } \\
\text { profile }\end{array}$ & $\begin{array}{l}\text { - Invasive BP } \\
\text { monitoring } \\
\text { - IV antihypertensive } \\
\text { agent } \\
\text { - Aim to reduce initial } \\
\text { MAP by no more } \\
\text { than } 25 \% \\
\text { - Avoid lowering } \\
\text { BP too much, too } \\
\text { quickly, as it may } \\
\text { lead to cerebral } \\
\text { ischemia }\end{array}$ \\
\hline $\begin{array}{l}\text { Hemiplegic } \\
\text { migraine }^{30,31}\end{array}$ & $\begin{array}{l}\text { - Start in the first or second } \\
\text { decade of life as sporadic or } \\
\text { familial } \\
\text { - Most patients also have } \\
\text { attacks of migraine with typi- } \\
\text { cal aura without weakness } \\
\text { - Aura consists of a fully revers- } \\
\text { ible motor weakness } \\
\text { - Weakness may resolve before } \\
\text { the headache starts or may } \\
\text { persist for days } \\
\text { - May be accompanied by ipsi- } \\
\text { lateral numbness or tingling, } \\
\text { with or without a speech } \\
\text { disturbance } \\
\text { - In familial hemiplegic migraine } \\
\text { (FHM), there is positive family } \\
\text { history in at least one first- or } \\
\text { second- degree relative }\end{array}$ & $\begin{array}{l}\text { - Neurological examina- } \\
\text { tion assessing for other } \\
\text { causes of hemiplegia } \\
\text { - The short time course } \\
\text { and full reversal } \\
\text { spontaneously }\end{array}$ & $\begin{array}{l}\text { - Diagnosis of } \\
\text { exclusion } \\
\text { - CT or MRI to } \\
\text { exclude other } \\
\text { etiologies } \\
\text { - Angiography to } \\
\text { rule out transient } \\
\text { ischemic attacks } \\
\text { and vascular } \\
\text { abnormality } \\
\text { - SPECT scan may } \\
\text { show hypoperfu- } \\
\text { sion during the } \\
\text { aura phase } \\
\text { - Genetic testing is } \\
\text { available for FHM }\end{array}$ & $\begin{array}{l}\text { - Early neurologist } \\
\text { involvement } \\
\text { - Antiemetics, nonste- } \\
\text { roidal anti-inflam- } \\
\text { matory drugs, and } \\
\text { nonnarcotic pain } \\
\text { relievers } \\
\text { - Prophylactic treat- } \\
\text { ment may include } \\
\text { lamotrigine and } \\
\text { acetazolamide }\end{array}$ \\
\hline
\end{tabular}

(continued) 
Table 3 (Continued)

\begin{tabular}{|c|c|c|c|c|}
\hline Disease & History & Examination & Investigation & Treatment \\
\hline \multicolumn{5}{|c|}{ Spinal cord lesions } \\
\hline $\begin{array}{l}\text { Spinal cord } \\
\text { infarction }^{32}\end{array}$ & $\begin{array}{l}\text { - Acute quadriparesis or para- } \\
\text { paresis with a sensory level } \\
\text { corresponding with level of } \\
\text { cord infarct } \\
\text { - No history of trauma or } \\
\text { infection } \\
\text { - } 60 \% \text { of patients present with } \\
\text { pain that localizes to the level } \\
\text { of injury } \\
\text { - May be associated with aortic } \\
\text { surgery or procedures such as } \\
\text { celiac ganglion ablation } \\
\text { - May be having risk factors } \\
\text { leading to hypercoagulable } \\
\text { states }\end{array}$ & $\begin{array}{l}\text { - May present with ante- } \\
\text { rior or posterior spinal } \\
\text { artery syndrome (A/ } \\
\text { PSAS) depending upon } \\
\text { the portion of spinal } \\
\text { cord involvement } \\
\text { - ASAS: loss of motor } \\
\text { power, usually bilateral } \\
\text { weakness, occasionally } \\
\text { unilateral } \\
\text { Initially flaccid paralysis } \\
\text { and loss of deep tendon } \\
\text { reflexes } \\
\text { Loss of pain/temperature } \\
\text { sensation } \\
\text { - PSAS: loss of proprio- } \\
\text { ception and vibratory } \\
\text { sense below the level of } \\
\text { the injury } \\
\text { Total anesthesia at the } \\
\text { level of injury } \\
\text { - Other variants possible }\end{array}$ & $\begin{array}{l}\text { - MRI: Ischemic } \\
\text { lesion matching } \\
\text { an arterial territo- } \\
\text { ry of the cord } \\
\text { - Spinal an- } \\
\text { giogram: as } \\
\text { suggested from } \\
\text { MRI to rule out } \\
\text { malformations } \\
\text { Other investiga- } \\
\text { tions to rule out } \\
\text { hypercoagulable } \\
\text { state: prothrom- } \\
\text { botic and vasculi- } \\
\text { tis screen } \\
\text { Toxicology screen } \\
\text { Electrocardiography } \\
\text { Echocardiography } \\
\text { Duplex ultrasonog- } \\
\text { raphy of the cervical } \\
\text { arteries } \\
\text { 24-hour Holter } \\
\text { electrocardiography }\end{array}$ & $\begin{array}{l}\text { - Supportive treat- } \\
\text { ment only } \\
\text { - Corticosteroids } \\
\text { are currently not } \\
\text { recommended } \\
\text { - Consider antiplatelet } \\
\text { agents in patients } \\
\text { with underlying vas- } \\
\text { cular risk factors } \\
\text { - Intervention di- } \\
\text { rected toward the } \\
\text { underlying lesion }\end{array}$ \\
\hline $\begin{array}{l}\text { Aortic } \\
\text { dissection }\end{array}$ & $\begin{array}{l}\text { - Severe, sharp or "tearing" } \\
\text { posterior chest or back pain } \\
\text { - May be associated with an } \\
\text { acute neurological deficit } \\
\text { - Neurological features may } \\
\text { include hemiplegia, monople- } \\
\text { gia, and paraplegia }\end{array}$ & $\begin{array}{l}\text { - One-third experiences } \\
\text { neurological deficits }{ }^{18} \\
\text { - } 10 \% \text { of type A dissec- } \\
\text { tions may present } \\
\text { with only neurological } \\
\text { manifestations } \\
\text { - Weak or absent pulse } \\
\text { (15.1\%) (carotid, brachi- } \\
\text { al, or femoral) } \\
\text { - Associated features } \\
\text { may include acute } \\
\text { myocardial infarction, } \\
\text { cardiac tamponade, } \\
\text { hemothorax, hypoten- } \\
\text { sion, pain, abdominal } \\
\text { pain, back or flank } \\
\text { pain, renal failure, or } \\
\text { Horner's syndrome }\end{array}$ & $\begin{array}{l}\text { - ECG to exclude } \\
\text { myocardial } \\
\text { infarction } \\
\text { - CXR for medias- } \\
\text { tinum widening } \\
\text { and hemothorax } \\
\text { - Bedside echocar- } \\
\text { diogram trans- } \\
\text { esophageal or } \\
\text { transthoracic } \\
\text { - CT aortogram } \\
\text { - CT head }\end{array}$ & $\begin{array}{l}\text { - Reduce systolic } \\
\text { blood pressure and } \\
\text { heart rate using IV } \\
\beta \text { blocker; consider } \\
\text { a nitroprusside } \\
\text { infusion; avoid } \\
\text { hydralazine } \\
\text { - Surgical intervention } \\
\text { as soon as possible } \\
\text { and if indicated }\end{array}$ \\
\hline
\end{tabular}

(continued) 
Table 3 (Continued)

\begin{tabular}{|c|c|c|c|c|}
\hline Disease & History & Examination & Investigation & Treatment \\
\hline $\begin{array}{l}\text { Brown- } \\
\text { Sequard } \\
\text { syndrome }^{36,37}\end{array}$ & $\begin{array}{l}\text { - Sudden onset hemiplegia with } \\
\text { contralateral loss of pain and } \\
\text { temperature }\end{array}$ & $\begin{array}{l}\text { - Ipsilateral weakness } \\
\text { - Ipsilateral loss of } \\
\text { proprioception and } \\
\text { vibratory sensation } \\
\text { - Contralateral loss of } \\
\text { pain and temperature } \\
\text { sensation } \\
\text { - Urinary bladder and } \\
\text { bowel involvement }\end{array}$ & $\begin{array}{l}\text { - MRI } \\
\text { - CT myelog- } \\
\text { raphy if MRI } \\
\text { contraindicated }\end{array}$ & $\begin{array}{l}\text { - Immobilization } \\
\text { - Surgery with spinal } \\
\text { cord decompression }\end{array}$ \\
\hline $\begin{array}{l}\text { Transverse } \\
\text { myelitis }{ }^{38}\end{array}$ & $\begin{array}{l}\text { - Isolated spinal cord dysfunc- } \\
\text { tion over hours or days } \\
\text { - Weakness and sensory distur- } \\
\text { bance below the level of the } \\
\text { lesion } \\
\text { - Back pain with bladder and } \\
\text { bowel dysfunction is common } \\
\text { - No evidence of compressive } \\
\text { lesion } \\
\text { - Segmental spinal cord injury } \\
\text { caused by acute inflammation } \\
\text { - Thoracic cord most commonly } \\
\text { involved } \\
\text { - } 50 \% \text { have preceding viral } \\
\text { infection }\end{array}$ & $\begin{array}{l}\text { - Evidence of myelop- } \\
\text { athy, with weakness } \\
\text { and sensory symptoms } \\
\text { corresponding to a } \\
\text { specific dermatomal } \\
\text { and myotomal level } \\
\text { - Increased or decreased } \\
\text { sensation with pares- } \\
\text { thesia may be present } \\
\text { - Urinary bladder and } \\
\text { bowel involvement }\end{array}$ & MRI is diagnostic & $\begin{array}{l}\text { - IV } \\
\text { methylprednisolone } \\
\text { - IVIG } \\
\text { - Plasma exchange }\end{array}$ \\
\hline $\begin{array}{l}\text { Amyotrophic } \\
\text { lateral sclero- } \\
\text { sis }(A L S)^{39-42}\end{array}$ & $\begin{array}{l}\text { - Progressive weakness which } \\
\text { may start in a limb } \\
\text { - May manifest by slurred } \\
\text { speech and dysphagia } \\
\text { - A small percentage may } \\
\text { have respiratory involvement } \\
\text { initially } \\
\text { - Other neurological symptoms: } \\
\text { changes in mental function } \\
\text { (e.g., dementia, pseudobulbar } \\
\text { affect } \\
\text { - Absence of alternative } \\
\text { diagnosis }\end{array}$ & $\begin{array}{l}\text { - A mixture of UMN signs } \\
\text { and LMN signs } \\
\text { - The sensory examina- } \\
\text { tion is usually normal } \\
\text { - Spares urinary bladder/ } \\
\text { bowel }\end{array}$ & $\begin{array}{l}\text { - Nerve conduction } \\
\text { studies } \\
\text { - Electromyography } \\
\text { (EMG) } \\
\text { - MRI (to exclude } \\
\text { other intracranial } \\
\text { lesions) } \\
\text { - To exclude other } \\
\text { diagnoses: an- } \\
\text { ti-GM1 antibody } \\
\text { (multifocal motor } \\
\text { neuropathy), SPEP } \\
\text { (multiple myelo- } \\
\text { ma, lymphoma), } \\
\text { heavy metals, } \\
\text { HIV, Lyme anti- } \\
\text { body, myasthenia } \\
\text { gravis } \\
\text { - Lumbar puncture: } \\
\text { HIV, Lyme disease } \\
\text { or chronic } \\
\text { Inflammatory } \\
\text { demyelinating }\end{array}$ & - Supportive care \\
\hline
\end{tabular}

(continued) 
Table 3 (Continued)

\begin{tabular}{|c|c|c|c|c|}
\hline Disease & History & Examination & Investigation & Treatment \\
\hline \multicolumn{5}{|c|}{ Peripheral nerve lesions } \\
\hline $\begin{array}{l}\text { Guillain-Barré } \\
\text { syndrome }{ }^{7,8,42-45}\end{array}$ & $\begin{array}{l}\text { - Precedental history of mild } \\
\text { respiratory or gastrointestinal } \\
\text { illness ( } 2-4 \text { weeks prior) } \\
\text { - Typically, symmetrical as- } \\
\text { cending paralysis with limb } \\
\text { paresthesia is common (80\%) } \\
\text { and pain } \\
\text { - Dysautonomia occurs in } 70 \% \\
\text { - Upper limb/facial weakness } \\
\text { (10\%) } \\
\text { - Respiratory failure ( 10\%) } \\
\text { - Oculomotor weakness (15\%) }\end{array}$ & $\begin{array}{l}\text { - Symmetrical ascending } \\
\text { paralysis } \\
\text { - Absent deep tendon } \\
\text { reflexes } \\
\text { - Miller Fisher syndrome } \\
\text { variant presents with } \\
\text { ophthalmoplegia, atax- } \\
\text { ia, and areflexia } \\
\text { - In acute motor axonal } \\
\text { neuropathy variant, } \\
\text { sensation is preserved } \\
\text { - Acute motor and sen- } \\
\text { sory axonal neuropathy } \\
\text { has more sensory } \\
\text { symptoms } \\
\text { - Other rarer variants } \\
\text { may exist }{ }^{40}\end{array}$ & $\begin{array}{l}\text { - CSF analysis: } \\
\text { elevated protein, } \\
\text { normal cell count } \\
\text { - Electromyography } \\
\text { - Nerve conduction } \\
\text { studies } \\
\text { - Glycolipid anti- } \\
\text { bodies may be } \\
\text { present in some } \\
\text { variants }\end{array}$ & $\begin{array}{l}\text { - Supportive care } \\
\text { - Plasma exchange } \\
\text { - IVIG } \\
\text { - No benefit for } \\
\text { corticosteroids }{ }^{41}\end{array}$ \\
\hline $\begin{array}{l}\text { Vasculitic } \\
\text { neuropathy }{ }^{46,47}\end{array}$ & $\begin{array}{l}\text { - May be part of systemic vascu- } \\
\text { litis or a nonsystemic vasculitic } \\
\text { neuropathy } \\
\text { - Asymmetric or multifocal pain- } \\
\text { ful sensorimotor neuropathy } \\
\text { - May present as mononeuritis } \\
\text { multiplex or a sensorimotor } \\
\text { neuropathy } \\
\text { - Sensory symptoms of pain, } \\
\text { burning, or paresthesias } \\
\text { precede and virtually always } \\
\text { present } \\
\text { - Weakness of muscles supplied } \\
\text { by the affected nerve } \\
\text { - Constitutional symptoms, in- } \\
\text { cluding weight loss, anorexia, } \\
\text { fatigue, arthralgia, myalgia, } \\
\text { and fever, occur in approxi- } \\
\text { mately two-thirds of patients }\end{array}$ & $\begin{array}{l}\text { - Flaccid asymmetric } \\
\text { paresis with sensory ab- } \\
\text { normalities in variable } \\
\text { distributions } \\
\text { - Lower limbs are more } \\
\text { commonly involved } \\
\text { - Distal involvement is } \\
\text { more frequent than } \\
\text { proximal } \\
\text { - Cranial nerve (facial) } \\
\text { may be involved in } 8 \% \\
\text { of patients }\end{array}$ & $\begin{array}{l}\text { - Vasculitic screen: } \\
\text { - Erythrocyte } \\
\text { sedimentation } \\
\text { rate } \\
\text { - Antinuclear } \\
\text { antibodies } \\
\text { - Extractable nu- } \\
\text { clear antigens } \\
\text { - Rheumatoid } \\
\text { factor } \\
\text { - Antineutrophil } \\
\text { - cytoplasmic an- } \\
\text { tibodies Serum } \\
\text { complement } \\
\text { - Serum immu- } \\
\text { nofixation/ } \\
\text { immunoelectro- } \\
\text { phoresis } \\
\text { - Quantitative } \\
\text { immuno- } \\
\text { globulins } \\
\text { Cryoglobulins } \\
\text { - Hepatitis B/C } \\
\text { antigen and } \\
\text { antibody } \\
\text { - Nerve conduction } \\
\text { studies } \\
\text { EMG } \\
\text { Nerve and muscle } \\
\text { biopsy }\end{array}$ & $\begin{array}{l}\text { - Combination thera- } \\
\text { py with steroids and } \\
\text { cyclophosphamide } \\
\text { - Treat neuropathic } \\
\text { pain with agents } \\
\text { such as } \\
\text { - Pregabalin } \\
\text { - Gabapentin } \\
\text { - Amitriptyline } \\
\text { - Nortriptyline } \\
\text { - Carbamazepine }\end{array}$ \\
\hline
\end{tabular}


Table 3 (Continued)

\begin{tabular}{|c|c|c|c|c|}
\hline Disease & History & Examination & Investigation & Treatment \\
\hline $\begin{array}{l}\text { Toxin-induced } \\
\text { peripheral } \\
\text { neuropathy }{ }^{48} \\
\text { (alcohol, } \\
\text { amiodarone, } \\
\text { chlorampheni- } \\
\text { col, disulfiram, } \\
\text { isoniazid, } \\
\text { lithium, met- } \\
\text { ronidazole, } \\
\text { nitrofurantoin, } \\
\text { nitrous oxide, } \\
\text { thalidomide, } \\
\text { vincristine, } \\
\text { thallium, etc.) }\end{array}$ & $\begin{array}{l}\text { - Many drugs and industrial } \\
\text { chemicals may cause distal } \\
\text { axonopathy } \\
\text { - Dose, duration of expo- } \\
\text { sure, and host factors affect } \\
\text { outcome } \\
\text { - Presentation with pain, pares- } \\
\text { thesia, and hypoesthesia in the } \\
\text { feet and distal weakness and } \\
\text { gait disturbance } \\
\text { - Autonomic dysfunction may } \\
\text { be present }\end{array}$ & $\begin{array}{l}\text { - Sensory changes in } \\
\text { glove and stocking } \\
\text { distribution } \\
\text { - Distal weakness that } \\
\text { progresses proximally } \\
\text { - Hyporeflexia, symmet- } \\
\text { rical loss of ankle jerks } \\
\text { first } \\
\text { - CNS may be involved }\end{array}$ & $\begin{array}{l}\text { - EMG (electromy- } \\
\text { ography) } \\
\text { - Nerve conduction } \\
\text { study } \\
\text { - Serum levels for } \\
\text { suspected toxin } \\
\text { - Consider nerve/ } \\
\text { muscle biopsies }\end{array}$ & $\begin{array}{l}\text { - Prevent ongoing } \\
\text { exposure } \\
\text { - Supportive care }\end{array}$ \\
\hline $\begin{array}{l}\text { Heavy metal } \\
\text { toxicity }{ }^{49-51}\end{array}$ & $\begin{array}{l}\text { - Peripheral neuropathies may } \\
\text { occur within a few hours to } \\
\text { days of acute high dose expo- } \\
\text { sure, especially lead, arsenic, } \\
\text { and thallium }{ }^{47} \\
\text { - Common presentation: } \\
\text { nausea, persistent vomiting, } \\
\text { diarrhea, and abdominal } \\
\text { pain, with encephalopathy, } \\
\text { cardiomyopathy, dysrhyth- } \\
\text { mias, acute kidney injury, and } \\
\text { metabolic acidosis }\end{array}$ & $\begin{array}{l}\text { - Lead neuropathy initial- } \\
\text { ly affects motor fibers } \\
\text { in radial and peroneal } \\
\text { distributions } \\
\text { - Mees lines (horizontal } \\
\text { hypopigmented lines } \\
\text { across all nails) } \\
\text { - Evidence of anemia } \\
\text { and other major organ } \\
\text { failures }\end{array}$ & $\begin{array}{l}\text { - CBC (anemia) with } \\
\text { blood film analysis } \\
\text { for basophilic stip- } \\
\text { pling (lead/arsenic } \\
\text { toxicity), } \\
\text { - Kidney and liver } \\
\text { function tests } \\
\text { and coagulation } \\
\text { studies } \\
\text { - Serum and urine } \\
\text { metal levels of } \\
\text { suspected metal }\end{array}$ & $\begin{array}{l}\text { - Stop further } \\
\text { exposure } \\
\text { - Consult toxicologist/ } \\
\text { poison center } \\
\text { - Symptomatic } \\
\text { treatment } \\
\text { - Consider chelation } \\
\text { therapy }\end{array}$ \\
\hline $\begin{array}{l}\text { Nerve com- } \\
\text { pression } \\
\text { syndromes } \\
\text { (median nerve } \\
\text { at wrist, ulnar } \\
\text { nerve at elbow } \\
\text { and wrist, radial } \\
\text { nerve in prox- } \\
\text { imal forearm, } \\
\text { scapular nerve, } \\
\text { lateral femo- } \\
\text { ral cutaneous } \\
\text { nerve, common } \\
\text { peroneal nerve, } \\
\text { tibial nerve, and } \\
\text { lower brachial } \\
\text { plexus) }\end{array}$ & $\begin{array}{l}\text { - History of acute or prolonged } \\
\text { neural pressure } \\
\text { - History depends on the region } \\
\text { involved } \\
\text { - Pain and paresthesias typically } \\
\text { precede hypoesthesia and } \\
\text { weakness/atrophy } \\
\text { - May be caused by systemic } \\
\text { conditions such as pregnancy, } \\
\text { obesity, hypothyroidism, and } \\
\text { diabetes } \\
\text { - Local causes such as prolapsed } \\
\text { intervertebral disc produces } \\
\text { symptoms in the affected } \\
\text { dermatome and myotome }\end{array}$ & $\begin{array}{l}\text { - Weakness in the mus- } \\
\text { cles supplied by the } \\
\text { affected nerve } \\
\text { - Flaccid, hypotonic, } \\
\text { hyporeflexic paralysis } \\
\text { - Sensory symptoms } \\
\text { include pain, paresthe- } \\
\text { sias, and hypoesthesia } \\
\text { - Wasting and atrophy if } \\
\text { long standing } \\
\text { - Skin changes include } \\
\text { dry, thin, hairless skin; } \\
\text { ridged, thickened, } \\
\text { cracked nails; and re- } \\
\text { current skin ulceration }\end{array}$ & $\begin{array}{l}\text { - Nerve conduction } \\
\text { studies } \\
\text { - } \mathrm{MRI} \\
\text { - EMG }\end{array}$ & $\begin{array}{l}\text { - Treat or remove } \\
\text { precipitants } \\
\text { - Decompressive sur- } \\
\text { gery if conservative } \\
\text { management fails }\end{array}$ \\
\hline
\end{tabular}


Table 3 (Continued)

\begin{tabular}{|c|c|c|c|c|}
\hline Disease & History & Examination & Investigation & Treatment \\
\hline \multicolumn{5}{|c|}{ Neuromuscular junction } \\
\hline Botulism ${ }^{53-55,56}$ & $\begin{array}{l}\text { - Descending symmetrical pa- } \\
\text { ralysis with a clear sensorium } \\
\text { and no fever } \\
\text { - No sensory deficits other than } \\
\text { blurred vision } \\
\text { - Foodborne } \\
\text { Seen after } 12-36 \text { hours of } \\
\text { ingestion } \\
\text { Prodromal symptoms } \\
\text { including nausea, vomiting, } \\
\text { abdominal pain, diarrhea, and } \\
\text { dry mouth with sore throat }{ }^{42} \\
\text { - Wound botulism } \\
\text { Follow deep infected regions } \\
\text { with the presence of spores } \\
\text { - Infantile botulism } \\
\text { Occurs from } 1 \text { week-1 year in } \\
\text { infants who are formula fed } \\
\text { - May present with constipation, } \\
\text { weakness, feeding difficul- } \\
\text { ties, descending or global } \\
\text { hypotonia, drooling, anorexia, } \\
\text { irritability, and weak cry43 }\end{array}$ & $\begin{array}{l}\text { - Cranial nerves first } \\
\text { affected: fixed dilated } \\
\text { pupils (causing blurred } \\
\text { vision), diplopia, } \\
\text { nystagmus, ptosis, } \\
\text { dysphagia, dysarthria, } \\
\text { and facial weakness } \\
\text { - Descending flaccid } \\
\text { paralysis } \\
\text { - May cause bladder and } \\
\text { bowel dysfunction }\end{array}$ & $\begin{array}{l}\text { - Stool, vomit, } \\
\text { suspected food } \\
\text { and wound de- } \\
\text { bridement looking } \\
\text { for C. botulinum } \\
\text { spores } \\
\text { - Serum assay for } \\
\text { botulinum toxin } \\
\text { - Pulmonary func- } \\
\text { tion tests }\end{array}$ & $\begin{array}{l}\text { - Adults/Children } \\
\text { >1 year: Equine } \\
\text { serum heptavalent } \\
\text { - Infants < 1 year: } \\
\text { Human-derived } \\
\text { botulism immune } \\
\text { globulin } \\
\text { - Penicillin G (or } \\
\text { metronidazole) for } \\
\text { wound }\end{array}$ \\
\hline $\begin{array}{l}\text { Tick } \\
\text { paralysis }^{57,58}\end{array}$ & $\begin{array}{l}\text { - Presents with unsteady gait } \\
\text { followed by an ascending sym- } \\
\text { metrical flaccid paralysis 2-6 } \\
\text { days post tick attachment } \\
\text { - Sensory symptoms: paresthe- } \\
\text { sias and hypoesthesia } \\
\text { - Anorexia, lethargy, drowsiness, } \\
\text { and confusion may precede } \\
\text { weakness } \\
\text { - Ataxia may be only symptom } \\
\text { - No fever }\end{array}$ & $\begin{array}{l}\text { - Tick found attached to } \\
\text { - Aatient } \\
\text { - Ascending symmetrical } \\
\text { - Hypotonic, hyporeflexic } \\
\text { - Progresses to affect all } \\
\text { cranial nerves including } \\
\text { pupillary dilatation } \\
\text { - Sensory function is gen- } \\
\text { erally preserved other } \\
\text { than mild paresthesias } \\
\text { and hypoesthesia }\end{array}$ & $\begin{array}{l}\text { - Locate tick } \\
\text { - EMG shows re- } \\
\text { duced amplitude } \\
\text { of compound } \\
\text { muscle action } \\
\text { potentials } \\
\text { - Labs, CSF analysis, } \\
\text { and MRI are typi- } \\
\text { cally normal }\end{array}$ & $\begin{array}{l}\text { - Paralyze tick with } \\
\text { insecticide and re- } \\
\text { move with forceps } \\
\text { - Supportive care }\end{array}$ \\
\hline $\begin{array}{l}\text { Organo- } \\
\text { phosphate } \\
\text { toxicity }\end{array}$ & $\begin{array}{l}\text { - Insecticide exposure (e.g., } \\
\text { malathion, parathion, diaz- } \\
\text { inon, fenthion, dichlorvos, } \\
\text { chlorpyrifos, ethion) } \\
\text { - Nerve gas exposure (e.g., } \\
\text { sarin, VX, soman, tabun) } \\
\text { - Ophthalmic agents (e.g., echo- } \\
\text { thiophate, isoflurophate) } \\
\text { - Antihelminthics (trichlorfon) }\end{array}$ & $\begin{array}{l}\text { - Fasciculations with } \\
\text { paralysis } \\
\text { - Cholinergic symp- } \\
\text { toms: Bronchospasm, } \\
\text { bradycardia, miosis, } \\
\text { lacrimation, saliva- } \\
\text { tion, bronchorrhea, } \\
\text { urination, emesis, and } \\
\text { diarrhea } \\
\text { - Decreased deep tendon } \\
\text { reflexes, } \\
\text { - cranial nerve abnormal- } \\
\text { ities including bulbar } \\
\text { palsy } \\
\text { - Respiratory } \\
\text { insufficiency } \\
\text { - Delayed ascending } \\
\text { flaccid paralysis may } \\
\text { develop }\end{array}$ & $\begin{array}{l}\text { - History of } \\
\text { exposure } \\
\text { - RBC acetyl } \\
\text { cholinesterase } \\
\text { (if available) for } \\
\text { severity and to } \\
\text { guide oxime } \\
\text { therapy }\end{array}$ & $\begin{array}{l}\text { - Remove contaminat- } \\
\text { ed clothes } \\
\text { - Care of airway, } \\
\text { breathing, and } \\
\text { circulation } \\
\text { - Atropine } 2-3 \text { mg IV } \\
\text { stat, then double } \\
\text { the dose every five } \\
\text { minutes until symp- } \\
\text { toms are controlled } \\
\text { - Pralidoxime } \\
\text { - Consider ben- } \\
\text { zodiazepines for } \\
\text { the prevention } \\
\text { and treatment of } \\
\text { seizures }\end{array}$ \\
\hline
\end{tabular}


Table 3 (Continued)

\begin{tabular}{|c|c|c|c|c|}
\hline Disease & History & Examination & Investigation & Treatment \\
\hline $\begin{array}{l}\text { Myasthenia } \\
\text { gravis }^{61,62}\end{array}$ & $\begin{array}{l}\text { - History of myasthenia gravis } \\
\text { - Acute decompensation } \\
\text { (myasthenic crisis) may be } \\
\text { spontaneous or precipitated } \\
\text { by infection, surgery, or taper- } \\
\text { ing of immunosuppression, } \\
\text { certain antibiotics and other } \\
\text { precipitating factors } \\
\text { - Excessive treatment with } \\
\text { cholinesterase inhibitors may } \\
\text { paradoxically cause weakness } \\
\text { (Cholinergic crisis) }\end{array}$ & $\begin{array}{l}\text { - } 85 \% \text { of patients have } \\
\text { involvement of the } \\
\text { eyelids and extra-ocular } \\
\text { muscles, resulting in } \\
\text { ptosis and/or diplopia23 } \\
\text { - Fatiguability } \\
\text { - Flaccid muscles } \\
\text { weakness } \\
\text { - Central muscles are } \\
\text { predominantly involved } \\
\text { such as bulbar muscles } \\
\text { - Neck and proximal limb } \\
\text { weakness may occur } \\
\text { - Respiratory failure } \\
\text { occurs in } 1 \% \\
\text { - Weakness increases } \\
\text { after exertion }\end{array}$ & $\begin{array}{l}\text { - Ice pack test (e.g., } \\
\text { ice on affected } \\
\text { eyelid improves } \\
\text { ptosis) } \\
\text { - ACh receptor anti- } \\
\text { bodies if diagnosis } \\
\text { uncertain } \\
\text { - Pulmonary func- } \\
\text { tion tests } \\
\text { - Consider arterial } \\
\text { blood gas } \\
\text { - Consider CT chest } \\
\text { (thymoma may } \\
\text { affect breathing) }\end{array}$ & $\begin{array}{l}\text { - For acute decom- } \\
\text { pensation, admit } \\
\text { to ICU } \\
\text { - Airway and ventila- } \\
\text { tion should be as- } \\
\text { sessed and managed } \\
\text { with either non-in- } \\
\text { vasive ventilation or } \\
\text { intubation } \\
\text { - Withdraw anti- } \\
\text { cholinesterase } \\
\text { medications } \\
\text { - Plasmapheresis or } \\
\text { IVIG } \\
\text { - High-dose steroids } \\
\text { - Consider other im- } \\
\text { munosuppressants }\end{array}$ \\
\hline $\begin{array}{l}\text { Lambert-Eaton } \\
\text { myasthenic } \\
\text { syndrome } \\
\text { (LEMS) }{ }^{63,64}\end{array}$ & $\begin{array}{l}\text { - In } 40 \% \text { of patients, small cell } \\
\text { lung cancer is present } \\
\text { - Progressive proximal lower } \\
\text { limb weakness } \\
\text { - Ptosis, diplopia, and dysarthria } \\
\text { as cranial nerves become } \\
\text { involved, (less common than } \\
\text { myasthenia gravis) } \\
\text { - Autonomic dysfunction } \\
\text { - Exacerbated by heat or fever } \\
\text { and certain drugs }\end{array}$ & $\begin{array}{l}\text { - Proximal muscle weak- } \\
\text { ness, lower limbs more } \\
\text { than upper } \\
\text { - Depressed tendon } \\
\text { reflexes } \\
\text { - Post-tetanic } \\
\text { potentiation } \\
\text { - Sensation preserved } \\
\text { - Respiratory failure rare }\end{array}$ & $\begin{array}{l}\text { - Voltage gated } \\
\text { calcium channel } \\
\text { antibodies } \\
\text { - AChR antibodies } \\
\text { - Repetitive nerve } \\
\text { stimulation } \\
\text { - EMG } \\
\text { - Look for ma- } \\
\text { lignancy with } \\
\text { imaging/ } \\
\text { Bronchoscopy }\end{array}$ & $\begin{array}{l}\text { - Confirm diagnosis } \\
\text { and distinguish from } \\
\text { myasthenia gravis } \\
\text { before starting } \\
\text { treatment } \\
\text { - Supportive } \\
\text { treatment } \\
\text { - Treat underlying } \\
\text { malignancy } \\
\text { - Consider } \\
\text { 3,4-diaminopyridine } \\
\text { - IVIG } \\
\text { - Plasma exchange }\end{array}$ \\
\hline \multicolumn{5}{|l|}{ Muscle } \\
\hline $\begin{array}{l}\text { Dermatomyo- } \\
\text { sitis }^{65}\end{array}$ & $\begin{array}{l}\text { - May present with skin and/or } \\
\text { muscle involvement } \\
\text { - Proximal muscle weakness } \\
\text { - Characteristic rash } \\
\text { - Systemic symptoms include } \\
\text { arthralgia, arthritis, dyspnea, } \\
\text { dysphagia, arrhythmia, and } \\
\text { dysphonia }\end{array}$ & $\begin{array}{l}\text { - Heliotrope rash } \\
\text { (blue-purple discol- } \\
\text { oration on the upper } \\
\text { eyelids) } \\
\text { - Raised, violaceous, } \\
\text { scaly eruption on the } \\
\text { knuckles (Gottron's } \\
\text { papules) } \\
\text { - Proximal symmetrical } \\
\text { muscle weakness } \\
\text { - Muscle pain and } \\
\text { tenderness } \\
\text { - Normal sensation and } \\
\text { tendon reflexes } \\
\text { - Joint swelling (particu- } \\
\text { larly of the hand) may } \\
\text { occur occasionally in } \\
\text { some patients }\end{array}$ & $\begin{array}{l}\text { - Elevated CK, } \\
\text { aldolase, lactate } \\
\text { dehydroge- } \\
\text { nase, or alanine } \\
\text { aminotransferase } \\
\text { - Auto-antibody } \\
\text { serology } \\
\text { - Skin biopsy } \\
\text { - Muscle biopsy } \\
\text { - NCS/EMG }\end{array}$ & $\begin{array}{l}\text { - Corticosteroids } \\
\text { - Consider immu- } \\
\text { nosuppressive or } \\
\text { cytotoxic steroid } \\
\text { sparing agents } \\
\text { - IVIG in refractory } \\
\text { cases }\end{array}$ \\
\hline
\end{tabular}


Table 3 (Continued)

\begin{tabular}{|c|c|c|c|c|}
\hline Disease & History & Examination & Investigation & Treatment \\
\hline \multicolumn{5}{|c|}{ Generalized weakness due to systemic causes } \\
\hline $\begin{array}{l}\text { Hyperglyce- } \\
\text { mia }^{66,67}\end{array}$ & $\begin{array}{l}\text { - History of diabetes } \\
\text { - Possible precipitating events } \\
\text { (e.g., infection, myocardial } \\
\text { infarction, surgery, critical } \\
\text { illness) } \\
\text { - Neurological symptoms } \\
\text { primarily occur when plasma } \\
\text { osmolality is greater than } 320 \\
\text { mOsmol/L } \\
\text { - Neurological symptoms may } \\
\text { include hemiparesis, focal } \\
\text { motor deficits, decreased con- } \\
\text { sciousness, and seizures } \\
\text { - May have polyuria, polydipsia, } \\
\text { and weight loss for several } \\
\text { days before presentation }\end{array}$ & $\begin{array}{l}\text { - Level of consciousness } \\
\text { may be reduced } \\
\text { - Focal motor and sen- } \\
\text { sory deficits including } \\
\text { aphasia, hyperreflexia, } \\
\text { hemianopia, and brain- } \\
\text { stem dysfunction } \\
\text { - Other findings asso- } \\
\text { ciated with DKA or } \\
\text { HHS include evidence } \\
\text { of volume depletion, } \\
\text { hyperventilation and } \\
\text { abdominal pain }\end{array}$ & $\begin{array}{l}\text { - Serum glucose } \\
\text { - Plasma osmolality } \\
\text { - Serum electro- } \\
\text { lytes (with anion } \\
\text { gap), urea, and } \\
\text { creatinine } \\
\text { - Urinalysis, and } \\
\text { urine/ serum ke- } \\
\text { tones by dipstick } \\
\text { - Blood gas } \\
\text { - Electrocardiogram } \\
\text { - CT head to ex- } \\
\text { clude other causes }\end{array}$ & $\begin{array}{l}\text { - Fluid replacement } \\
\text { to correct hy- } \\
\text { pervolemia and } \\
\text { hyperosmolality } \\
\text { - Insulin infusion } \\
\text { - Close monitoring } \\
\text { of urine output and } \\
\text { electrolytes (potas- } \\
\text { sium, magnesium, } \\
\text { and phosphate) } \\
\text { - Treat precipitating } \\
\text { cause }\end{array}$ \\
\hline $\begin{array}{l}\text { Hypoglyce- } \\
\text { mia (serum } \\
\text { glucose<3 } \\
\text { mmol/L; }<50 \\
\text { mg/dL) }\end{array}$ & $\begin{array}{l}\text { - Diabetes } \\
\text { - Insulin regimen } \\
\text { - Oral hypoglycemics } \\
\text { - Alcohol } \\
\text { - Sepsis } \\
\text { - Liver disease } \\
\text { - Hypocortisolemia }\end{array}$ & $\begin{array}{l}\text { - Decreased } \\
\text { consciousness } \\
\text { - Many forms of focal } \\
\text { neurological deficit } \\
\text { possible, which may } \\
\text { mimic } \\
\text { - Dysphoria } \\
\text { - Seizures stroke } \\
\text { - Tremor, palpitations, } \\
\text { anxiety, sweating, hun- } \\
\text { ger, and paresthesia }\end{array}$ & $\begin{array}{l}\text { - Blood glucose } \\
\text { level } \\
\text { - CT head to rule } \\
\text { out intracranial } \\
\text { causes }\end{array}$ & $\begin{array}{l}\text { - IV dextrose } \\
\text { - Oral if patient is } \\
\text { conscious } \\
\text { - Alternatively, } 1 \mathrm{mg} \\
\text { glucagon IM or IV }\end{array}$ \\
\hline $\begin{array}{l}\text { Hyponatremia, } \\
\text { hypernatre- } \\
\text { mia }\end{array}$ & $\begin{array}{l}\text { - Hyponatremia: diuretic } \\
\text { overdose, hypervolemia, CHF, } \\
\text { cirrhosis, SIADH, cerebral salt } \\
\text { wasting and water intoxication } \\
\text { - Hypernatremia: dehy- } \\
\text { dration, pituitary insuffi- } \\
\text { ciency, iatrogenic sodium } \\
\text { supplementation } \\
\text { - Lethargy and confusion are } \\
\text { most common followed by } \\
\text { seizures and coma in both } \\
\text { extremes }\end{array}$ & $\begin{array}{l}\text { Depressed level of con- } \\
\text { sciousness or delirium }\end{array}$ & $\begin{array}{l}\text { - Serum sodium } \\
\text { levels }\end{array}$ & $\begin{array}{l}\text { - Hyponatremia: } \\
\text { fluid restriction, stop } \\
\text { diuretics, avoid rapid } \\
\text { correction } \\
\text { - Hypernatremia: IV } \\
\text { fluids if hypovole- } \\
\text { mic, prefer hypo- } \\
\text { tonic solutions (5D, } \\
0.45 \% \text { NS), avoid } \\
\text { rapid correction } \\
\text { if urine specif- } \\
\text { ic gravity is low } \\
\text { (pituitary insuffi- } \\
\text { ciency): administer } \\
\text { desmopressin }\end{array}$ \\
\hline $\begin{array}{l}\text { Hypermagne- } \\
\text { semia }^{71}\end{array}$ & $\begin{array}{l}\text { - Typically follows excessive } \\
\text { magnesium administration } \\
\text { (e.g., management of pre-ec- } \\
\text { lampsia) in context of renal } \\
\text { impairment } \\
\text { - Lethargy and confusion are } \\
\text { most common neurologic } \\
\text { manifestations followed by } \\
\text { generalized weakness, and } \\
\text { respiratory failure }\end{array}$ & $\begin{array}{l}\text { - Hyporeflexia: (early } \\
\text { sign) loss of deep ten- } \\
\text { don reflexes } \\
\text { - Flaccid tetraparesis } \\
\text { involving all muscle } \\
\text { groups } \\
\text { - Lethargy, confusion }\end{array}$ & $\begin{array}{l}\text { Serum magnesium } \\
\text { levels }\end{array}$ & $\begin{array}{l}\text { - Stop magnesium } \\
\text { administration } \\
\text { - IV calcium } \\
\text { gluconate/chloride } \\
\text { - IV fluids } \\
\text { - Consider dialysis }\end{array}$ \\
\hline
\end{tabular}


Table 3 (Continued)

\begin{tabular}{|c|c|c|c|c|}
\hline Disease & History & Examination & Investigation & Treatment \\
\hline $\begin{array}{l}\text { Hypophospha- } \\
\text { temia }\end{array}$ & $\begin{array}{l}\text { Causes of hypophosphatemia } \\
\text { include: } \\
\text { - Intracellular shift: refeed- } \\
\text { ing syndrome, respiratory } \\
\text { alkalosis, diabetic ketoaci- } \\
\text { dosis, rapidly growing ma- } \\
\text { lignancies, osmotic diuresis, } \\
\text { malabsorption, renal tubular } \\
\text { acidosis } \\
\text { - Increased urinary excre- } \\
\text { tion: primary or secondary } \\
\text { hyperparathyroidism, osmot- } \\
\text { ic diuresis, renal tubular aci- } \\
\text { dosis, transplanted kidneys, } \\
\text { Fanconi syndrome, etc. } \\
\text { - Decreased intestinal } \\
\text { absorption: diarrhea, mal- } \\
\text { absorption syndromes, } \\
\text { phosphate binders } \\
\text { - Decreased dietary intake: } \\
\text { anorexia nervosa or chronic } \\
\text { alcoholism, Hypothermia } \\
\text { - Painful proximal myopathy } \\
\text { Other symptoms: changes } \\
\text { in mental function, seizures, } \\
\text { neuropathies, arrhythmias, } \\
\text { skeletal muscle weakness, } \\
\text { respiratory failure, rhabdomy- } \\
\text { olysis, leucocyte dysfunction, } \\
\text { sepsis, and sudden death } \\
\end{array}$ & $\begin{array}{l}\text { - Proximal muscle weak- } \\
\text { ness is common } \\
\text { - Any muscle group may } \\
\text { be involved in various } \\
\text { combinations, ranging } \\
\text { from ophthalmoplegia } \\
\text { to proximal myopathy } \\
\text { to dysphagia or ileus } \\
\text { - Weakness may be } \\
\text { so profound as to } \\
\text { mimic Guillain-Barre } \\
\text { syndrome } \\
\text { - Neurological features: } \\
\text { Confusion, seizures, } \\
\text { and coma } \\
\text { - Cardiac contractility } \\
\text { may be impaired lead- } \\
\text { ing to global myocardial } \\
\text { depression }\end{array}$ & $\begin{array}{l}\text { - Serum phosphate } \\
\text { - Hypercalcemia or } \\
\text { Hypomagnese- } \\
\text { mia is commonly } \\
\text { associated } \\
\text { - Other electrolytes } \\
\text { - Rhabdomyolysis } \\
\text { screen }\end{array}$ & $\begin{array}{l}\text { - Correct precipitant } \\
\text { - Replace total body } \\
\text { phosphate with } \\
\text { careful IV sodi- } \\
\text { um or potassium } \\
\text { phosphate }\end{array}$ \\
\hline $\begin{array}{l}\text { Periodic paral- } \\
\text { ysis (PP) }{ }^{74}\end{array}$ & $\begin{array}{l}\text { - Repeated episodes of flaccid } \\
\text { muscle weakness occurring at } \\
\text { irregular intervals with normal } \\
\text { strength between episodes } \\
\text { - Usually hereditary } \\
\text { - Various types of periodic paral- } \\
\text { ysis exist, including: } \\
\text { - Hyperkalemic PP } \\
\text { - Hypokalemic PP } \\
\text { - Paramyotonia congenita } \\
\text { - Thyrotoxic PP } \\
\text { - Andersen-Tawil syndrome } \\
\text { - Look for precipitating factor } \\
\text { (e.g., post exercise, fasting, } \\
\text { cold alcohol, stress, and dura- } \\
\text { tion of episode) }\end{array}$ & $\begin{array}{l}\text { - All forms usually } \\
\text { exhibit: } \\
\text { - Interictal lid lag and } \\
\text { eyelid myotonia } \\
\text { - Normal sensation } \\
\text { - Fixed proximal } \\
\text { weakness } \\
\text { - Diminished reflexes } \\
\text { during episode } \\
\text { - Normal power in be- } \\
\text { tween the episodes }\end{array}$ & $\begin{array}{l}\text { - Serum potassium } \\
\text { - Elevated creatine } \\
\text { kinase (CK) } \\
\text { - Potassium: creati- } \\
\text { nine ratio } \\
\text { - Blood gas analysis } \\
\text { for evidence of } \\
\text { concomitant } \\
\text { metabolic acidosis } \\
\text { or alkalosis } \\
\text { - ECG } \\
\text { - EMG } \\
\text { - Nerve conduction } \\
\text { studies }\end{array}$ & $\begin{array}{l}\text { - Hyperkalemic PP: } \\
\text { - High carbohydrate } \\
\text { food } \\
\text { - Thiazide or } \\
\text { acetazolamide } \\
\text { - Hypokalemic PP: } \\
\text { - Potassium } \\
\text { supplementation } \\
\text { - Acetazolamide } \\
\text { - Thyrotoxic PP: } \\
\text { - Beta blockers } \\
\text { - Treat } \\
\text { thyrotoxicosis } \\
\text { - Andersen-Tawil } \\
\text { syndrome: } \\
\text { - Acetazolamide }\end{array}$ \\
\hline
\end{tabular}

(continued) 
Table 3 (Continued)

\begin{tabular}{|c|c|c|c|c|}
\hline Disease & History & Examination & Investigation & Treatment \\
\hline \multicolumn{5}{|c|}{ Miscellaneous } \\
\hline $\begin{array}{l}\text { Envenom- } \\
\text { ation }^{75,76}\end{array}$ & $\begin{array}{l}\text { - Snake bite }{ }^{16} \\
\text { - Scorpion sting } \\
\text { - Marine envenomation } \\
\text { - Ingestion of puffer fish }\end{array}$ & $\begin{array}{l}\text { - Snake bites }{ }^{16} \text { : } \\
\text { Cardiovascular: hypo- } \\
\text { tension, shock, arrest } \\
\text { - Neurological: paral- } \\
\text { ysisptosis, diplopia, } \\
\text { bulbar palsy, dys- } \\
\text { arthria; respiratory } \\
\text { muscle paralysis } \\
\text { Coagulopathy: intra- } \\
\text { cranial hemorrhage, } \\
\text { bleeding from bite } \\
\text { site, ecchymoses, } \\
\text { bleeding gums, } \\
\text { hemarthroses } \\
\text { Rhabdomyolysis: } \\
\text { tender muscles } \\
\text { Scorpion sting: cranial } \\
\text { nerve and somatic } \\
\text { skeletal neuromuscular } \\
\text { dysfunction, with pain } \\
\text { and paresthesia } \\
\text { Blue-ringed octopus } \\
\text { and puffer fish enven- } \\
\text { omation: descending } \\
\text { symmetrical flaccid } \\
\text { paralysis with clear } \\
\text { sensorium, nausea, } \\
\text { and vomiting, blurred } \\
\text { vision, ataxia, respirato- } \\
\text { ry failure } \\
\text { Stonefish envenom- } \\
\text { ation: weakness in the } \\
\text { affected limb, severe } \\
\text { pain, shock }\end{array}$ & $\begin{array}{l}\text { - Serial bedside pul- } \\
\text { monary function } \\
\text { tests if descending } \\
\text { paralysis } \\
\text { - Other investiga- } \\
\text { tions as CBC, LFTs, } \\
\text { CK, whole blood } \\
\text { clotting time, co- } \\
\text { agulation, screen, } \\
\text { D-dimer, fibrin- } \\
\text { ogen levels, uri- } \\
\text { nalysis for blood } \\
\text { (myoglobin), } \\
\text { Head-CT if de- } \\
\text { creased GCS } \\
\text { Use venom de- } \\
\text { tection kit for bite } \\
\text { swab and urine }\end{array}$ & $\begin{array}{l}\text { - Supportive care of } \\
\text { airway, breathing, } \\
\text { and circulation } \\
\text { - Pressure immobiliza- } \\
\text { tion bandage } \\
\text { - Specific antivenom }\end{array}$ \\
\hline $\begin{array}{l}\text { Locked-in } \\
\text { syndrome }\end{array}$ & $\begin{array}{l}\text { - Sudden onset tetraplegia, } \\
\text { facial weakness, and horizontal } \\
\text { gaze palsy } \\
\text { - Causes ischemic stroke (most } \\
\text { common), central pontine } \\
\text { myelinolysis, encephalitis, or } \\
\text { tumor }\end{array}$ & $\begin{array}{l}\text { - Flaccid symmetrical } \\
\text { tetraparesis } \\
\text { - Consciousness } \\
\text { preserved or may be } \\
\text { affected initially but } \\
\text { returns to normal } \\
\text { - Voluntary vertical eye } \\
\text { and eyelid movements } \\
\text { preserved } \\
\text { - Hearing, vision, } \\
\text { pupillary reflexes, and } \\
\text { sensation all normal }\end{array}$ & $\begin{array}{l}\text { - } \text { CT brain with } \\
\text { spiral CT } \\
\text { angiography35 } \\
\text { - } \text { MRI/MRA }\end{array}$ & $\begin{array}{l}\text { Follow acute stroke } \\
\text { protocol }\end{array}$ \\
\hline
\end{tabular}


Table 3 (Continued)

\begin{tabular}{|c|c|c|c|c|}
\hline Disease & History & Examination & Investigation & Treatment \\
\hline $\begin{array}{l}\text { Acute } \\
\text { porphyria }^{78}\end{array}$ & $\begin{array}{l}\text { - Abdominal pain: may begin } \\
\text { in chest or back and move to } \\
\text { abdomen } \\
\text { - Gastrointestinal symptoms } \\
\text { such as vomiting, diarrhea, } \\
\text { and constipation are common } \\
\text { - Psychiatric symptoms } \\
\text { - Acute weakness (early or late) } \\
\text { - May develop seizures } \\
\text { - Certain medications are } \\
\text { known to exacerbate }\end{array}$ & $\begin{array}{l}\text { - Muscle weakness } \\
\text { usually begins proxi- } \\
\text { mally and more often in } \\
\text { upper limbs } \\
\text { - Symmetrical hypotonia } \\
\text { - Hyporeflexic } \\
\text { - Flaccid paralysis } \\
\text { - No rash unlike other } \\
\text { forms of porphyria } \\
\text { - Tachycardia and hyper- } \\
\text { tension may be present }\end{array}$ & $\begin{array}{l}\text { - Hyponatremia } \\
\text { - Urine: dark/ } \\
\text { reddish } \\
\text { - Urine analy- } \\
\text { sis: increased } \\
\text { porphobilinogen }\end{array}$ & $\begin{array}{l}\text { - IV hemin } \\
\text { - Manage } \\
\text { hyponatremia } \\
\text { - Consider antiepilep- } \\
\text { tic drugs } \\
\text { - Supportive } \\
\text { management }\end{array}$ \\
\hline $\begin{array}{l}\text { Diabetic } \\
\text { lumbosacral } \\
\text { radiculoplexus } \\
\text { neuropathy }{ }^{79}\end{array}$ & $\begin{array}{l}\text { - Diabetes mellitus with proxi- } \\
\text { mal weakness } \\
\text { - Asymmetrical pain in the hip, } \\
\text { buttock, or thigh } \\
\text { - Associated with poor glycemic } \\
\text { control } \\
\text { - Patients without distal sym- } \\
\text { metrical polyneuropathy most } \\
\text { often have sudden, unilateral } \\
\text { onset } \\
\text { - Occasionally may be initial pre- } \\
\text { sentation of diabetes mellitus }\end{array}$ & $\begin{array}{l}\text { - Proximal lower limb } \\
\text { muscle weakness and } \\
\text { wasting } \\
\text { - Minimal sensory loss is } \\
\text { observed } \\
\text { - Knee-jerk reflex is } \\
\text { absent, with commonly } \\
\text { preserved ankle jerks } \\
\text { - Ankle jerks may also be } \\
\text { absent, with underly- } \\
\text { ing distal symmetrical } \\
\text { polyneuropathy }\end{array}$ & $\begin{array}{l}\text { - Fasting blood glu- } \\
\text { cose and glycated } \\
\text { hemoglobin } \\
\text { - Imaging of lum- } \\
\text { bo-sacral spine } \\
\text { to exclude other } \\
\text { causes } \\
\text { - EMG } \\
\text { - Nerve conduction } \\
\text { studies }\end{array}$ & $\begin{array}{l}\text { - Optimize glycemic } \\
\text { control } \\
\text { - Physical and occupa- } \\
\text { tional therapy }\end{array}$ \\
\hline $\begin{array}{l}\text { Psychiatric } \\
\text { illness }\end{array}$ & $\begin{array}{l}\text { - No history suggestive of any } \\
\text { physical illness } \\
\text { - Temporal associations with } \\
\text { psychosocial stressors } \\
\text { - Symptom substitution fre- } \\
\text { quently present } \\
\text { - Primary psychological or per- } \\
\text { sonal gain present }\end{array}$ & $\begin{array}{l}\text { - La belle indifference } \\
\text { present } \\
\text { - Distribution does not } \\
\text { follow anatomical } \\
\text { pattern } \\
\text { - Presence of affective or } \\
\text { emotional disturbanc- } \\
\text { es on mental status } \\
\text { examination }\end{array}$ & \begin{tabular}{|l|} 
- Relevant investi- \\
gations to rule out \\
organic lesions \\
like (MRI/CT, EEG). \\
- Visual-evoked \\
potentials and \\
brainstem \\
auditory evoked \\
responses to rule \\
out malingering/ \\
compensation \\
neurosis
\end{tabular} & $\begin{array}{l}\text { - Minimize and } \\
\text { stop further } \\
\text { investigations } \\
\text { - Decrease secondary } \\
\text { gains } \\
\text { - Increase functioning } \\
\text { - Refer for special- } \\
\text { ist psychiatric } \\
\text { interventions }\end{array}$ \\
\hline
\end{tabular}

Source: Adapted with permission from Caulfield et al. ${ }^{3}$

Abbreviations: AChR, acetylcholine receptor; ASAS, anterior spinal artery syndrome; BP, blood pressure; CBC, complete blood count; CHF, congestive heart failure; CNS, central nervous system; CSF, cerebrospinal fluid; CT, computed tomography; DKA, diabetes ketoacidosis; ECG, electrocardiography; EEG, electroencephalogram; EMG, electromyography; GCS, Glasgow Coma Scale; HHC, hyperosmolar coma; HIV, human immuno-deficiency virus; HTN, hypertension; ICP, intracranial pressure; IV, intravenous; IVIG, intravenous immunoglobulin; LL, lower limb; LMN, lower motor neuron; MRA, magnetic resonance angiography; MRI, magnetic resonance imaging; NCS, nerve conduction study; PSAS, posterior spinal artery; SIAD, syndrome of inappropriate antidiuretic hormone secretion; SPECT, single-photon emission computed tomography; UL, Upper limb; UMN, upper motor neuron. 


\section{Special Consideration in Pediatric Patients}

The basic principles of assessment of the airway/ventilation and localization are the same as in adults. The major differences are in the presentation, and the common etiologies leading to weakness are highlighted here. In children, the presenting symptoms may be mutable such as irritability, agitation, restlessness, refusal to walk, frequent awakening from sleep, willingness to be held frequently, or regression of milestones. The history should focus on the evaluation of various risk factors such as congenital heart diseases, sickle cell anemia, and prothrombotic states. The examination of reflexes, signs of bulbar weakness, and assessment of sensory level are as critical as in adults, but it may be difficult in very young children. In children, it is difficult to distinguish the various causes of difficulty in walking such as weakness, pain, and ataxia.

The common causes of ANTW in children include Todd's paresis, acute demyelinating encephalomyelitis, acute transverse myelitis, GBS, and myasthenia gravis. ${ }^{19-23}$ Stroke is a rare presentation in children but may occur in various conditions including sickle cell, congenital heart disease, prothrombotic disorder, and Moyamoya disease. The aortic dissection is quite common ischemic spinal cord injury in children leading to spinal artery infarcts. If reflexes are intact, then consider transverse myelitis, Todd's paresis, myasthenia gravis or stroke, while in patients with reduced or absent reflexes, consider early transverse myelitis with spinal shock or GBS. Imaging modalities and laboratory tests should be directed as per the differential diagnosis.

\section{Referral to a Higher Center}

Healthcare providers should provide the following details including patient's age, history of present illness, complete details of patient's initial assessment (ABC), salient history, examination findings, laboratory reports, imaging results, and treatment provided. The further plan about a pending investigations, list of potential considerations, and management (if the diagnosis of acute weakness is known) should also be provided.

\section{Conclusion}

Acute nontraumatic muscle weakness occurs due to a lesion in the motor tract anywhere from pyramidal cells to peripheral muscles. These may prove to be life threatening if airway, breathing, or circulation is affected. Care of $A B C$ takes priority over managing and localizing the weakness. We should focus on a detailed history and examination to localize the lesion quickly, make an initial working diagnosis, and screen the patients for time-sensitive emergencies. The laboratory tests and neurological imaging are done to make the diagnosis. A systematic algorithm/protocol should be followed so that we do not miss any important cause of weakness.

\section{Conflict of Interest}

None declared.

\section{References}

1 Gerard T, Bryan D, Principles of Anatomy \& Physiology. 14th ed. New Jersey: John Wiley \& Sons, Inc; 2014:406, 502, 541

2 Gillian P, Christopher R, Human Physiology: The Basis of Medicine. 3rd ed. Oxford: Oxford University Press; 2006;151-153

3 Caulfield AF, Flower O, Pineda JA, Uddin S. Emergency neurological life support: acute non-traumatic weakness. Neurocrit Care 2017;27(Suppl 1):29-50

4 Mehta S. Neuromuscular disease causing acute respiratory failure. Respir Care 2006;51(9):1016-1021, discussion 1021-1023

5 Lawn ND, Fletcher DD, Henderson RD, Wolter TD, Wijdicks EF. Anticipating mechanical ventilation in Guillain-Barré syndrome. Arch Neurol 2001;58(6):893-898

6 Coplin WM, Pierson DJ, Cooley KD, Newell DW, Rubenfeld GD. Implications of extubation delay in brain-injured patients meeting standard weaning criteria. Am J Respir Crit Care Med 2000;161(5):1530-1536

7 Ropper AH. The Guillain-Barré syndrome. N Engl J Med 1992;326(17):1130-1136

8 Seneviratne U. Guillain-Barré syndrome. Postgrad Med J 2000;76(902):774-782

9 Sagarin MJ, Barton ED, Chng YM, Walls RM; National Emergency Airway Registry Investigators. Airway management by US and Canadian emergency medicine residents: a multicenter analysis of more than 6,000 endotracheal intubation attempts. Ann Emerg Med 2005;46(4):328-336

10 Li J, Murphy-Lavoie H, Bugas C. Martinez J, Preston C. Complications of emergency intubation with and without paralysis. Am. J Emerg Med 1999;17(2):141-143

11 Sakles JC, Laurin EG, Rantapaa AA, Panacek EA. Airway management in the emergency department: a one-year study of 610 tracheal intubations. Ann Emerg Med 1998;31(3):325-332

12 Walls RM. Rapid-sequence intubation in head trauma. Ann Emerg Med 1993;22(6):1008-1013

13 Abel M, Eisenkraft JB. Anesthetic implications of myasthenia gravis. Mt Sinai J Med 2002;69(1)(2):31-37

14 Orebaugh SL. Succinylcholine: adverse effects and alternatives in emergency medicine. Am.J Emerg Med 1999;17(7):715-721

15 Rajajee V, Riggs B, Seder DB. Emergency neurological life support: airway, ventilation, and sedation. Neurocrit Care 2017;27(Suppl 1):4-28

16 Jan MM, Al-Buhairi AR, Baeesa SS. Concise outline of the nervous system examination for the generalist. Neurosciences (Riyadh) 2001;6(1):16-22

17 Florman JE, Duffau H, Rughani AI. Lower motor neuron findings after upper motor neuron injury: insights from postoperative supplementary motor area syndrome. Front Hum Neurosci 2013;7:85

18 Folks DG, Ford CV, Regan WM. Conversion symptoms in a general hospital. Psychosomatics 1984;25(4):285-289, 291, 294-295

19 Zuccoli G, Panigrahy A, Bailey A, Fitz C. Redefining the Guillain-Barré spectrum in children: neuroimaging findings of cranial nerve involvement. Am J Neuroradiol 2011;32(4):639-642

20 Pidcock FS, Krishnan C, Crawford TO, Salorio CF, Trovato M, Kerr DA. Acute transverse myelitis in childhood: center-based analysis of 47 cases. Neurology 2007;68(18):1474-1480

21 Chen L, Li J, Guo Z, Liao S, Jiang L. Prognostic indicators of acute transverse myelitis in 39 children. Pediatr Neurol 2013;49(6):397-400

22 Wolf VL, Lupo PJ, Lotze TE. Pediatric acute transverse myelitis overview and differential diagnosis. J Child Neurol 2012;27(11):1426-1436

23 Bernard TJ, Rivkin MJ, Scholz K, et al; Thrombolysis in Pediatric Stroke Study. Emergence of the primary pediatric stroke center: impact of the thrombolysis in pediatric stroke trial. Stroke 2014;45(7):2018-2023

24 DeAngelis LM. Brain tumors. NEnglJ Med 2001;344(2):114-123 
25 Muzumdar D, Jhawar S, Goel A. Brain abscess: an overview. Int J Surg 2011;9(2):136-144

26 Gallmetzer P, Leutmezer F, Serles W. Assem-Hilger E, Spatt J, Baumgartner C. Postictal paresis in focal epilepsies-incidence, duration, and causes: a video-EEG monitoring study. Neurology 2004;62(12):2160-2164

27 Rolak LA, Rutecki P, Ashizawa T, Harati Y. Clinical features of Todd's post-epileptic paralysis. J Neurol Neurosurg Psychiatry 1992;55(1):63-64

28 Aggarwal M, Khan IA. Hypertensive crisis: hypertensive emergencies and urgencies. Cardiol Clin 2006;24(1):135-146

29 Vaughan CJ, Delanty N. Hypertensive emergencies. Lancet 2000;356(9227):411-417

30 Headache Classification Subcommittee of the International Headache, Society. The International Classification of Headache Disorders: 2nd edition. Cephalalgia 200;424(Suppl 1): 9-160

31 Russell MB, Ducros A. Sporadic and familial hemiplegic migraine: pathophysiological mechanisms, clinical characteristics, diagnosis, and management. Lancet Neurol 2011;10(5):457-470

32 Novy J, Carruzzo A, Maeder P, Bogousslavsky J. Spinal cord ischemia: clinical and imaging patterns, pathogenesis, and outcomes in 27 patients. Arch Neurol 2006;63(8):1113-1120

33 Hagan PG, Nienaber CA, Isselbacher EM, et al. The International Registry of Acute Aortic Dissection (IRAD): new insights into an old disease. JAMA 2000;283(7):897-903

34 Gaul C, Dietrich W, Friedrich I, Sirch J, Erbguth FJ. Neurological symptoms in type A aortic dissections. Stroke 2007;38(2):292-297

35 Tsai TT, Nienaber CA, Eagle KA. Acute aortic syndromes. Circulation 2005;112(24):3802-3813

36 Sayer FT, Vitali AM, Low HL, Paquette S, Honey CR. BrownSèquard syndrome produced by $\mathrm{C} 3-\mathrm{C} 4$ cervical disc herniation: a case report and review of the literature. Spine 2008;33(9):E279-E282

37 Antich PA, Sanjuan AC, Girvent FM, Simó JD. High cervical disc herniation and Brown-Sequard syndrome. A case report and review of the literature. J Bone Joint Surg $\mathrm{Br}$ 1999;81(3):462-463

38 Brinar VV, Habek M, Brinar M, Malojcić B, Boban M. The differential diagnosis of acute transverse myelitis. Clin Neurol Neurosurg 2006;108(3):278-283

39 Rowland LP, Shneider NA. Amyotrophic lateral sclerosis. N Engl J Med 2001;344(22):1688-1700

40 Kiernan MC, Vucic S, Cheah BC, et al. Amyotrophic lateral sclerosis. Lancet 2011;377(9769):942-955

41 Miller RG, Jackson CE, Kasarskis EJ, et al; Quality Standards Subcommittee of the American Academy of Neurology. Practice parameter update: the care of the patient with amyotrophic lateral sclerosis: multidisciplinary care, symptom management, and cognitive/behavioral impairment (an evidence-based review): report of the Quality Standards Subcommittee of the American Academy of Neurology. Neurology 2009;73(15):1227-1233

42 Meena AK, Khadilkar SV, Murthy JM. Treatment guidelines for Guillain-Barré Syndrome. Ann Indian Acad Neurol 2011;14(Suppl 1):S73-S81

43 Alshekhlee A, Hussain Z, Sultan B, Katirji B. Guillain-Barré syndrome: incidence and mortality rates in US hospitals. Neurology 2008;70(18):1608-1613

44 Ropper AH. Further regional variants of acute immune polyneuropathy. Bifacial weakness or sixth nerve paresis with paresthesias, lumbar polyradiculopathy, and ataxia with pharyngeal-cervical-brachial weakness. Arch Neurol 1994;51(7):671-675

45 Hughes RA, Swan AV, van Koningsveld R, van Doorn PA. Corticosteroids for Guillain-Barré syndrome. Cochrane Database Syst Rev 2006;19(2):CD001446
46 Davies L, Spies JM, Pollard JD, McLeod JG. Vasculitis confined to peripheral nerves. Brain 1996;119(Pt 5):1441-1448

47 Mathew L, Talbot K, Love S, Puvanarajah S, Donaghy M. Treatment of vasculitic peripheral neuropathy: a retrospective analysis of outcome. QJM 2007;100(1):41-51

48 London Z, Albers JW. Toxic neuropathies associated with pharmaceutic and industrial agents. Neurol Clin 2007;25(1):257-276

49 Graeme KA, Pollack CV, Jr. Heavy metal toxicity, part I: arsenic and mercury. J Emerg Med 1998;16(1):45-56

50 Graeme KA, Pollack CV, Jr. Heavy metal toxicity, part II: lead and metal fume fever. J Emerg Med 1998;16(2):171-177

51 Marx A, Glass JD, Sutter RW. Differential diagnosis of acute flaccid paralysis and its role in poliomyelitis surveillance. Epidemiol Rev 2000;22(2):298-316

52 Fox IK, Mackinnon SE. Adult peripheral nerve disorders: nerve entrapment, repair, transfer, and brachial plexus disorders. Plast Reconstr Surg 2011;127(5):105

53 Neal S, Fields KB. Peripheral nerve entrapment and injury in the upper extremity. Am Fam Physician 2010;81(2):147-155

54 Varma JK, Katsitadze G, Moiscrafishvili M, et al. Signs and symptoms predictive of death in patients with foodborne botulism-Republic of Georgia, 1980-2002. Clin Infect Dis 2004;39(3):357-362

55 Long SS. Infant botulism. Pediatr Infect Dis J 2001;20(7): 707-709

56 Chalk C, Benstead TJ, Keezer M. Medical treatment for botulism. Cochrane Database Syst Rev 2011 ;16(3):CD008123

57 Grattan-Smith PJ, Morris JG, Johnston HM, et al. Clinical and neurophysiological features of tick paralysis. Brain 1997;120(Pt 11):1975-1987

58 Edlow JA, McGillicuddy DC. Tick paralysis. Infect Dis Clin North Am 2008;22(3):397-413, vii

59 Eddleston M, Buckley NA, Eyer P, Dawson AH. Management of acute organophosphorus pesticide poisoning. Lancet 2008;371(9612):597-607

60 Roberts DM, Aaron CK. Management of acute organophosphorus pesticide poisoning. BMJ 2007;334(7594):629-634

61 Grob D, Brunner N, Namba T, Pagala M. Lifetime course of myasthenia gravis. Muscle Nerve 2008;37(2):141-149

62 Meriggioli MN, Sanders DB. Advances in the diagnosis of neuromuscular junction disorders. Am J Phys Med Rehabil 2005;84(8):627-638

63 Wirtz PW, Smallegange TM, Wintzen AR, Verschuuren JJ. Differences in clinical features between the Lambert-Eaton myasthenic syndrome with and without cancer: an analysis of 227 published cases. Clin Neurol Neurosurg 2002;104(4):359-363

64 Keogh M, Sedehizadeh S, Maddison P. Treatment for LambertEaton myasthenic syndrome. Cochrane Database Syst Rev 2011

65 Iorizzo LJ, III. Jorizzo JL. The treatment and prognosis of dermatomyositis: an updated review. J Am Acad Dermatol 2008;59(1):99-112

66 Guisado R, Arieff AI. Neurologic manifestations of diabetic comas: correlation with biochemical alterations in the brain. Metabolism 1975;24(5):665-679

67 Kitabchi AE, Umpierrez GE, Miles JM, Fisher JN. Hyperglycemic crises in adult patients with diabetes. Diabetes Care 2009;32(7):1335-1343

68 DeRosa MA, Cryer PE. Hypoglycemia and the sympathoadrenal system: neurogenic symptoms are largely the result of sympathetic neural, rather than adrenomedullary, activation. Am J Physiol Endocrinol Metab 2004;287(1):E32-E41

69 Reynolds RM, Padfield PL, Seckl JR. Disorders of sodium balance. BMJ 2006;332(7543):702-705

70 Adrogué HJ, Madias NE. Hypernatremia. N Engl J Med 2000;342(20):1493-1499

71 Riggs JE. Neurologic manifestations of electrolyte disturbances. Neurol Clin 2002;20(1):227-239 
72 Ravid M, Robson M. Proximal myopathy caused by latrogenic phosphate depletion. JAMA 1976;236(12):1380-1381

73 Sebastian S, Clarence D, Newson C. Severe hypophosphataemia mimicking Guillain-Barré syndrome. Anaesthesia 2008;63(8):873-875

74 Venance SL, Cannon SC, Fialho D, et al; CINCH investigators. The primary periodic paralyses: diagnosis, pathogenesis and treatment. Brain 2006;129(Pt 1):8-17

75 White J. Venomous animals: clinical toxinology. EXS 2010;100:233-291
76 Warrell DA. Snake bite. Lancet 2010;375(9708):77-88

77 Bruno MA, Pellas F, Schnakers C, et al. [Blink and you live: the locked-in syndrome] Rev Neurol (Paris) 2008;164(4):322-335

78 Anderson KE, Bloomer JR, Bonkovsky HL, et al. Recommendations for the diagnosis and treatment of the acute porphyrias. Ann Intern Med 2005;142(6):439-450

79 Tracy JA, Dyck PJ. The spectrum of diabetic neuropathies. Phys wwMed Rehabil Clin N Am 2008;19(1):1-26, v 